NASA Contractor Report 182231

\title{
Local-Global Analysis of Crack Growth in Continuously Reinforced Ceramic Matrix Composites
}

\author{
(HASA-CB-182231) LOCLL-GLCEAL IHALYSIS CF \\ N89-13820 \\ CEACK GEOATH IH CCATINUOOSLY EEIMECBCED \\ CERALIC GATRIX CCEFOSITES Final Eeport \\ (Case Hestern Beserve Oniv.) z6 F CSCL 20K \\ Unclas \\ $63 / 39$ \\ 0183397
}

Roberto Ballarini and Shamin Ahmed

Case Western Reserve University

Cleveland, Ohio

December 1988

Prepared for

Lewis Research Center

Under Grant NAG3-856

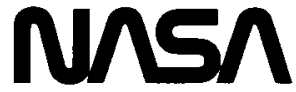

National Aeronautics and

Space Administration 
LOCAL-GLOBAL ANALYSIS OF CRACK GROWTH IN CONTINUOUSLY REINFORCED CERAMIC MATRIX COMPOSITES

\author{
Roberto Ballarini and Shamim Ahmed \\ Department of Civil Engineering \\ Case Western Reserve University \\ Cleveland, Ohio 44106
}

ABSTRACT

This paper describes the development of a mathematical model for predicting the strength and micromechanical failure characteristics of continuously reinforced ceramic matrix composites. The local-global andlysis models the vicinity of a propagating crack tip as a local heterogeneous region (LHR) consisting of spring-like representation of the matrix, fibers and interfaces. This region is embedded in an anisotropic continuum (representing the bulk composite) which is modeled by conventional finite elements.

Parametric studies are conducted to investigate the effects of LHR size, component properties, interface conditions, etc. On the strength and sequence of the failure processes in the unidirectional composite system. The results are compared with those predicted by the models developed by Marshall et al. (1985) and by Budiansky et al. (1986).

\section{INTRODUCTION}

The failure characteristics of fiber reinforced composites are dictated by various micromechanical failure processes such as matrix microcracking, slipping between matrix and fibers, delamination and fiber breakage. This paper presents a local-global model (it combines micromechanical and macromechanical analyses) which considers the vicinity of a crack tip a "process zone" capable of modeling such phenomena. Of special interest to our study are quantities such as critical matrix cracking stresses, since such damage leads to oxidation and eventually to fiber degradation, and is therefore used as an important criteria in design. Also of interest is the global response of the system to external loads (axial $P-\delta$ curves) and the ultimate load that the composite can sustain.

Before presenting a detailed description of the present model, a comparative review of existing models for fracture mechanics of brittle matrix composites (BMC) is warranted. The most quoted models are those developed by Aveston et a1. (1971), Marshall et al. (1985) and Budiansky et al. (1986). The following are some of the key concepts underlined in these models which we shall seek to study or validate through our model.
Marshall et al. (1985) have developed a model which can be used to predict the stress at which a matrix crack propagates across the specimen. This stress will, henceforth, be called the critical matrix cracking stress, omat. In their analysis, a frictional bond between fibers and matrix was assumed whereby slipping takes place when the interface shear stress reaches a critical value. Using a stress intensity factor approach, they have shown that a distinction needs to be made between short and long cracks. Short cracks are those for which the entire crack length contributes to the stress intensity factor as a result of fiber bridging, and therefore propagate at a stress which depends on the crack length. Long cracks experience a crack mouth displacement which asymptotically approaches a constant value $u_{0}$. This limiting displacement is reached at a distance $c_{0}$ from the crack tip. For such cracks, $\sigma_{\text {mat }}$ is independent of the crack length, since the contribution to the stress intensity factor from the fibers is limited to the length co behind the crack tip. It is important to note that this model implicitiy assumes the stressstrain diagram shown in $F i g$. $l(a)$, since no nonlinearities are assumed prior to the matrix cracking stresses. It will be shown using the model proposed in this paper that this assumption leads to a good estimate of o mat. However, for various constituent properties the present model shows that significant nonlinearities may occur prior to o mat (Fig. I(b)). These irreversible deformations, which are due to slipping between fiber and matrix and microcracking may prove to be significant for fatigue types of loading.

Budiansky et al. (1986) have considered steady state matrix cracking stresses for two conditions: (1) unbonded, frictionally constrained fibers, where the frictional restraint is the same as in Marshall et al. (1985); and (2) initially bonded fibers which debond due to crack tip stresses. The analysis is based on the Griffith energy criterion which considers the change in potential energy with respect to crack growth. The critical cracking condition is associated with the upstream and downstream stress states, far ahead of and behind the crack front. 
For case (1), the results generalize those of the ACK theory by considering matrix cracking stresses for conditions which lie between the no-slip and the large slip cases. They showed that the critical cracking stress, o mat, can be obtained using the graph shown in Fig. 2 in conjunction with Eqs. (1) and (2). The procedure includes first evaluating the two parameters $\sigma_{0}$ and $\sigma_{1}$ given by

$$
\begin{gathered}
\frac{\sigma_{0}}{E}=B\left[\frac{6 v_{f}^{2} E_{f}}{v_{m}^{2} E\left(1+v_{m}\right)}\right]^{1 / 4}\left[\frac{G_{m}}{r E_{m}}\right]^{1 / 2}, \\
\frac{\sigma_{1}}{E}=\left[\frac{6 v_{f}^{2} E_{f} \tau_{0}}{v_{m} E E_{m}}\right]^{1 / 3}\left[\frac{G_{m}}{r E_{m}}\right]^{1 / 3}
\end{gathered}
$$

where $B$ is a utility constant given by

$$
B=\left[\frac{2 v_{m}^{3}}{-6 \ln \left(v_{f}\right)-3 v_{m}\left(3-v_{f}\right)}\right]^{1 / 4},
$$

$E_{f}$ and $E_{m}$ are the Young's moduli of the fiber and matrix, $E$ is the composite modulus using the rule of mixtures, $v_{f}$ and $v_{m}$ are fiber and matrix volume fractions respectively, $r$ is the fiber radius, $G_{m}$ is the critical strain energy release rate of the matrix, and $\tau_{0}$ is the interface shear strength.

It is observed that for $\sigma_{1} / \sigma_{0} \leq 1.0$, the ACK expression for large slip cracking stress is recovered, i.e.,

$$
\sigma_{m a t}=\left[\frac{\sigma v_{f}^{2} E_{f} \tau_{0}\left(K_{I C}^{M}\right)^{2}\left(1-v_{m}^{2}\right)}{v_{m} E_{m}^{3} E r}\right]^{1 / 3} E,
$$

where $\left(K_{I C}^{M}\right)$ is the fracture toughness of the matrix. The ratio $\sigma_{1} / \sigma_{0}$ is then calculated and Fig. 2 is used to obtain the corresponding value of $\sigma_{\text {mat }} / \sigma_{0}$.

For bonded-debonding fibers, the following expression was derived:

$$
\frac{\sigma_{m a t}}{\sigma_{0}}=\left\{\frac{1+\frac{4 v_{f}}{v_{m}}\left(\frac{1}{r}\right)\left(\frac{G_{d}}{G_{m}}\right)}{1+\frac{B^{2}}{v_{m}}\left[\frac{6 E}{\left(1+v_{m}\right) E_{f}}\right]^{1 / 2}\left(\frac{1}{r}\right)}\right\}^{1 / 2},
$$

where $l_{d}$ is the debond length and $G_{d}$ is the critical energy release rate of the interface.

Expressions for the slip length Is $_{\mathrm{s}}$ (case (1)) and debond length $l_{d}$ (case (2)) will be discussed subsequently.

This paper presents the preliminary results obtained using a model which can be used to predict the fracture characteristics of reinforced ceramic matrix composites. This model has been used to simulate an experiment in which a notched specimen is subjected to tensile stresses. The results are compared to those obtained using the aforementioned models.

\section{THE LOCAL MOOEL}

The local heterogeneous region (LHR) shown in Fig. 3 consists of three distinct components: fibers, matrix, and fiber-matrix interface. Following Kanninen et al. (1977), each component is assumed homogeneous and isotropic and is modeled by a succession of rectangular spring elements (Fig. 4).

Each LHR spring element consists of four extensional springs and one rotary spring at each of the corner nodes. Each node has 2 degrees of freedom as shown in Fig. 5. An assembly of such elements behaves like a homogeneous anisotropic continuum in a state of plane deformation.

The stiffness matrix of a LHR element is given by

$$
\{F\}=[K]\{d\} \text {, }
$$

where $\{F\}$ is the nodal force vector, [K] is the element stiffness matrix, and $\{d\}$ is the nodal displacement vector.

The LHR element spring stiffnesses are related to the elastic properties of the material. The derivations for the spring stiffnesses and for the LHR stiffness matrix are given in Appendix $A$.

Each LHR fiber and matrix element is capable of fracturing in either of the four possible modes shown in Fig. 6. Modes 1 and 2 correspond to crack growth in the $x$-direction by an amount $a / 2$, while modes 3 and 4 represent cracking in the y-direction within the element by a length of $b / 2$, where $a$ and $b$ are the length and width, respectively, of a LHR element. These damage lengths have been used for the sake of simplicity in representing fracture events in the LHR elements. Each event contributes to a loss of stiffness of the element, and consequently leads to a change in the strain energy, $\Delta E_{s}$, given by:

$$
\Delta E_{S}=\frac{\{u\}^{\top}[\delta K]\{u\}}{2 \Delta c}
$$

where $\{u\}$ is the displacement vector of the element,

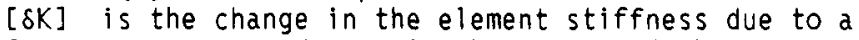
fracture event, and $\Delta c$ is the length of the crack in the element, $i . e ., a / 2$ or $b / 2$. The above relationship is derived in Appendix $B$.

It is assumed that for each material (fiber and matrix) a critical rupture energy is known. This provides a decision rule for breakage in each separate element of the LHR.

For purposes of comparison with the results of Marshall et al. (1985), preliminary simulations were conducted assuming that fiber slipping occurs at a critical shear stress $\tau_{0}$. In subsequent studies, more realistic modeling which includes delamination and an elastic-plastic friction model will be employed.

\section{THE LOCAL-GLOBAL MODEL}

A schematic representation of a typical localglobal model is shown in Fig. 7 (not to scale). The notched composite specimen modeled has a length $1=20 \mathrm{~cm}$ and width $w=5 \mathrm{~cm}$. The LHR surrounds the crack tip and is embedded in the bulk anisotropic composite, discretized by standard four-node constant strain isoparametric finite elements. The LHR and the outer zone are coupled through the enforcement of displacement compatibility at the nodes between the LHR and standard finite elements. 
The specimen is loaded incrementally in tension perpendicular to the crack plane and parallel to the direction of the fibers. Displacements are evaluated at every nodal point in the LHR, and the strain energy associated with each possible rupture event in every LHR element is calculated. The critical rupture energies of the fiber and matrix elements are obtained from their fracture toughnesses as follows

$$
\left(E_{c r}^{m, f}\right)=\frac{\left(K_{I C}^{M, F}\right)^{2}}{(E)_{m, f}} \times(\Delta C) \times\left(1-v_{m, f}^{2}\right)
$$

where $K_{I C}^{M}\left(K_{I C}^{F}\right)$ is the fracture toughness of the matrix (fiber) material, $E_{c r}^{m}\left(E_{c r}^{f}\right)$ is the critical energy for a given length of damage growth within the matrix (fiber) LHR element; and $v_{m}\left(\nu_{f}\right)$ is the Poisson's ratio of the matrix (fiber).

The critical regions, if any exist, are allowed to fracture in any one of the four modes described earlier and appropriate modifications are made in the LHR stiffness matrix.

As stated earlier, failure of the interface elements is based on the interfacial shear stress criteria. For each load level, the shear stress $\tau$ xy is computed in every LHR interface element and this value is compared to the prescribed critical shear stress $\tau_{0}$. If $\tau_{x y}<\tau_{0}$ (no-slip condition) relative displacement between the fiber and matrix is constrained. For elements where $\tau_{x y} \geq \tau_{0}$, the fiber is allowed to slip through the matrix and appropriate changes are made in the shear stiffness of the interface element so that slip takes place at a constant shear stress $\tau_{x y}=\tau_{0}$.

The solution procedure is repeated for the next load increment to reflect additional local rupture events. The progression of the main crack through the matrix (and eventually through the fibers) is followed by expanding the LHR zone continuously. The load at which the LHR elements begin to fail without any further increment of load is recorded as the ultimate strength of the composite. This is generally found to occur at a stage when the main crack has broken through four (or sometimes less) successive fibers.

RESULTS

\section{Physical Properties and Parameters}

Most of the results presented in this paper assume material properties (refer to Table I) obtained from the following sources: Weeton et al. (1986), DiCarlo (1984), and Bubsey et al. (1983).

Two fiber volume fractions were considered, 0.2 and 0.4 . Consistent with the ve values were the properties of the anisotropic bulk composite:

$$
\begin{aligned}
v_{f}=0.2: \quad E_{y y}=242.8 \mathrm{GPa} ; E_{x x} & =227.47 \mathrm{GPa} ; \\
v_{x y} & =0.3 ; G_{x y}=100.42 \mathrm{GPa} \\
v_{f}=0.4: \quad E_{y y}=279.6 \mathrm{GPa} ; E_{x x} & =253.92 \mathrm{GPa} ; \\
v_{x y} & =0.3 ; G_{x y}=112.93 \mathrm{GPa}
\end{aligned}
$$

The interface shear strength, $\tau_{0}$, was varied in the practical range of 0 to $10 \mathrm{MPa}$. The fracture toughness of the matrix was also varied from 1.0 to $5.0 \mathrm{MPa} \sqrt{\mathrm{m}}$.
The diameter of the SiC fibers (2r) was taken as $100 \mathrm{\mu m}$. Assumption of regular hexagonal packing arrangement gave an interfiber distance of about 213 and $150 \mu \mathrm{m}$ (center to center) for volume fractions of 0.2 and 0.4 , respectively. The interface was assumed to have a nominal thickness of $5 \mu \mathrm{m}$.

To investigate the convergence of the local-global model, ultimate and matrix cracking stresses were studied for various LHR sizes. Figure 8 shows the effect of starting LHR size on the ultimate stress ${ }^{\circ} u l t$ and the critical matrix cracking stress, omat. Convergence is observed for LHR lengths greater than about $1000 \mu \mathrm{m}$ and hence LHR sizes of the order of 1000 to $1500 \mu \mathrm{m}$ were used throughout the study.

\section{Comparisons With Results Obtained by Marshall et al. (1985)}

Effect of crack length. As mentioned previously, Marshall et al. (1985) have shown that when the crack length is greater than a certain characteristic size, matrix cracking stresses are independent of the crack length $c$. To check this result, critical matrix cracking stresses ( $\sigma_{\text {mat }}$ ) were calculated for various crack sizes. For the case $\tau_{0}=10 \mathrm{MPa}, K_{I C}^{\mathrm{M}}=4.6 \mathrm{MPa} \sqrt{\mathrm{m}}$ and $v_{f}=0.4$, the results are presented in $\mathrm{Fig} .9$. Though o $\sigma_{\text {mat }}$ is high for small crack lengths, it is found to be independent of crack length for $c \geq 0.046 \mathrm{~cm}$. This compares favorably to the steady state crack length proposed by Marshall et al. (1985) obtained from the relation

$$
c \cong \frac{1}{3}\left(\frac{\pi}{4 I^{4 / 3}}\right)\left[\frac{K^{M} C_{m} v_{m}^{2}(1+\eta) r}{\tau_{0} v_{f}^{2} E_{f}\left(1-v_{m}^{2}\right)}\right]^{2 / 3}
$$

$$
\cong 0.034 \mathrm{~cm} \text {. }
$$

where $n=v_{f} E_{f} / v_{m} E_{m}, K_{I C}^{M}$ is the fracture toughness of the matrix, and $I$ is 1.2 for straight cracks.

It should be noted that Eq. ( 8 ) was derived by assuming that the matrix stress intensity factor, $K_{I}^{M}$, is related to the composite stress intensity, $K_{I}^{L}$, by the relation $K_{I}^{M}=K_{I}^{L} E_{m} / E$. This relation is not valid uniess the crack length is of the order of several fiber spacings. In a future communication, the range of validity of this equation will be reported. Effect of matrix fracture toughness on $\sigma_{\text {mat }}$ and oult. Having obtained the steady state crack length, the critical matrix cracking stress, omat, and ultimate strength of the composite, $\sigma_{u l t}$, were investigated next using an initial crack length such that steady state conditions are obtained. The ultimate strength and $\sigma_{\text {mat }}$ depend on several constituent material properties such as fracture toughness of the components, interface shear strength, fiber spacing and volume fraction of the fibers etc. Each of these parameters are considered separately. The variation of $\sigma_{\text {mat }}$ with $K_{I C}^{M}$ over the range 1.0 to $5.0 \mathrm{MPa} \sqrt{\mathrm{m}}$ is studied for a notch length of $1 \mathrm{~cm}$ and interfacial shear strength of $10 \mathrm{MPa}$. The critical matrix cracking stress is found to increase with $K_{I C}^{M}$ and the results compare well with those of Marshall et al. (1985) given by 


$$
\sigma_{m a t}=1.83\left[\frac{\left(1-v_{m}^{2}\right)\left(K_{I C}^{M}\right)^{2} \tau_{0} E_{f} v_{f}^{2} v_{m}(1+n)^{2}}{E_{m} r}\right]^{1 / 3}
$$

The results from our model and those obtained from the above relationship are shown in Fig. 10 . Since the results of Marshall et al. (1985) and Budiansky et al. (1986) are almost equivalent, they do not plot as separate curves. The ultimate strength is not affected significantly by variation in $K_{I C}^{M}$, since the ultimate strength of the composite is controlled primarily by the fiber-bundle strength. If $l_{u}$ is the length of the initially uncracked ligament in the notched specimen of width $w$, the bundle strength is given by $\sigma_{f} v_{f}\left(l_{u} / w\right)$, where $\sigma_{f}$ is the tensile strength of the fibers. For the $\mathrm{SiC}$ fibers, $\sigma_{f}=1.83 \mathrm{GPa}$. Hence, for a notch length of $1 \mathrm{~cm}$ and $w=5 \mathrm{~cm}$, the theoretical bundle strength is $586 \mathrm{MPa}$ for $v_{f}=0.4$, and $293 \mathrm{MPa}$ for $v_{f}=0.2$. The ultimate composite strength, $\sigma_{u l t}$, obtained using our model is slightly less than these calculated values. This is due to the sequential breakage of the fibers leading to catastrophic failure.

Effect of interfacial shear strength. Since interface shear strengths are difficult to estimate, a parametric study was conducted for $\tau_{0}$ ranging from 5.0 to $10.0 \mathrm{MPa}$. The variation of $\sigma_{\text {mat }}$ with $\tau_{0}$, shown in Fig. 11, shows good agreement with results obtained by Marshall et al. (1985) using Eq. (9).

Effect of fiber volume fraction. Two fiber volume fractions $v_{f}$ were considered, 0.2 and 0.4 . The fiber volume fraction controls the interfiber spacing and its effects on $\sigma_{\text {mat }}$ and $\sigma_{u l t}$ with respect to $K_{I C}^{M}$ and $\tau_{0}$ are presented in Figs. 12(a) and (b). It is observed that $\sigma_{\text {mat }}$ and $\sigma_{u l t}$ values for $v_{f}=0.2$ are approximately half of those for $v_{f}=0.4$. These results agree with those obtained using Eq. (9).

Variation of crack mouth opening displacement with crack iength. Another key concept introduced in the model developed by Marshall et al. (1985), is that of the equilibrium crack opening $u=u_{0}$ for long cracks. To study the effect of crack length on $u$, the crack opening displacement at the mouth of the crack was recorded for various crack lengths (Fig. 13). Although $u$ increases with increasing crack length for crack lengths less than $1 \mathrm{~cm}$, it appears to approach a constant value of approximately $1 \mu \mathrm{m}$ for crack lengths greater than that size. This value may be compared to the limiting displacement $u_{0}$ estimated by Marshal? et al. (1985) by the relationship

$$
u_{0}=\frac{\sigma^{2} r}{\left\{4 \tau_{0} v_{f}^{2} E_{f}(1+\eta)\right\}}
$$

where $\sigma$ is the farfield applied load. For $\sigma=\sigma_{\text {mat }}$ $=300 \mathrm{MPa}, \tau_{0}=10 \mathrm{MPa}$, and $v_{f}=0.4, u_{0} \approx 0.8 \mu \mathrm{m}$. The agreement is quite good.

Comparison with Results Obtained by Budiansky et al. $(1986)$

Comparison of critical matrix cracking stress $\sigma_{\text {mat. The critical matrix cracking stresses obtained }}$ using our model are compared to those obtained by Budiansky et al. (1986) for unbonded composites
(Eqs. (1) to (3)). Because their results lead to predictions equivalent to those of Marshall et al. (1985) they plot as the same curve in Figs. 10 and 11 .

Comparison of slip lengths. For unbonded composites, the slip length has been derived by Budiansky et al. (1986) as

$$
\frac{l_{s}}{r}=\frac{\sigma v_{m} E_{m}}{2 v_{f} E_{0}}-\frac{1}{\rho},
$$

where $l_{s}$ is the slip length on either side of the crack face, $\sigma$ is the applied stress, and

$$
\rho=\frac{B^{2}}{v_{m}}\left[\frac{6 E}{E_{f}\left(1+v_{m}\right)}\right]^{1 / 2}
$$

For $\tau_{0}=10 \mathrm{MPa}, \mathrm{K}_{\mathrm{IC}}^{\mathrm{M}}=4.6 \mathrm{MPa} \sqrt{\mathrm{m}}$; and $\sigma=\sigma_{\text {mat }}$ $300 \mathrm{MPa}, \mathrm{I}_{\mathrm{s}}=806 \mu \mathrm{m}$.

Results of our simulation are schematically presented in Fig. 14. The slip length is approximately 900 to $1000 \mu \mathrm{m}$ on either side of the crack face, which agrees quite well with the result of Budiansky et al. (1986).

\section{Composite Failure Sequence}

While the existing models are concerned only with the steady state condition, the present model enables a detailed study of the failure sequence as the specimen is loaded incrementally. A schematic representation of the failure events in the LHR for a notch

length of $1 \mathrm{~cm}, \tau_{0}=10 \mathrm{MPa}, K_{I C}^{M}=4.6 \mathrm{MPa} \sqrt{\mathrm{m}}$ is shown in Fig. 14. Slipping first occurs at an applied stress of $140 \mathrm{MPa}$, and the interface continues to slip with increasing load. The first matrix crack is observed around the crack tip at a stress of $295 \mathrm{MPa}$. For matrices with lower $K_{I C}^{M}$, some microcracking is observed around the crack tip before the growth of the main crack. The matrix crack steadily progresses through the composite section and traverses it completely at a critical matrix cracking stress of about $305 \mathrm{MPa}$ $\left(\sigma_{\text {mat }}\right)$. As the load is increased, several secondary matrix cracks appear in the matrix. The first fiber failure occurs at a load of $505 \mathrm{MPa}$, and in general, this occurs at a load of about 90 percent of the ultimate stress. With increasing load, the crack breaks through three successive fibers before catastrophic failure occurs at an ultimate stress of $550 \mathrm{MPa}$.

\section{Load-Deflection Behavior}

The load-deflection curves as functions of the interfacial shear strength are shown in Fig. 15. Except for the case $\tau_{0}=0$, it is observed that nonlinearities begin at point (a) before $\sigma_{\text {mat }}$ is reached. This decrease in stiffness is a result of fiber sipping and matrix microcracking. A further reduction in stiffness occurs at region (b). This region corresponds to extensive matrix cracking through the section of the composite, so that the load is now essentially carried by the fibers. The ultimate failure load $\left(\sigma_{u l t}\right)$ is reached at $(c)$.

\section{CONCLUSION}

A model is presented which can be used to predict the failure characteristics of fiber reinforced composites. Preliminary results obtained using the model compare favorably with those predicted by existing 
models. This model may be generalized to consider more complicated geometries and loading conditions as well as the behavior of composites containing a random distribution of microflaws and strengths. It has been suggested (Dollar and Steif, 1988) that assumption of constant interface shear strength may not be accurate. The model is currently being improved through the implementation of more realistic interfacial constitutive modeling. In subsequent work, special friction interface elements developed by Plesha et al. (1987) will be used.

\section{ACKNOWLEDGMENTS}

The authors are grateful for support from NASA Lewis Research Center (Grant NAG3-856) and for the assistance provided by Professor Robert Mullen, Civil Engineering Department, CWRU in the computational aspects of this work.

\section{REFERENCES}

Aveston, J., Cooper, G.A., and Kelly, A., 1971, "Single and Multiple Fracture," The Properties of Fibre Composites, IPC Science and Technology Press, Guildford, England, pp. 15-26.

Bubsey, R.T., Shannon, J.L., Jr., and Munz, D., 1983, "Development of Plane Strain Fracture Toughness Test for Ceramics Using Chevron Notched Specimens," Ceramics for High Performance Applications III: Reliability, E.M. Lenoe, R.N. Katz, and J.J. Burke, eds., Plenum Press, NY, pp. 753-77i.

Budiansky, B., Hutchinson, J.W., and Evans, A.G., 1986. "Matrix Fracture in Fiber-Reinforced Ceramics," Journal of the Mechanics and Physics of Solids, Vol. 34, No. 2, pp. 167-189.

DiCarlo, J.A., 1984, "High Performance Fibers for Structurally Reliable Metal and Ceramic Composites," NASA Report, TM-86878.

Dollar, A., and Steif, P.S., 1988, "Load Transfer in Composites With a Coulomb Friction Interface," International Journal of Solids and Structures, Vol. 24, No. 8, pp. 789-803

Kanninen, M.F., Rybicki, E.F., and Griffith, W.I. 1977, "Preliminary Development of a Fundamental Analysis Model for Crack Growth in a Fiber Reinforced Composite Material," Composite Materials: Testing and Design (Fourth Conference), ASTM STP 617. American Society for Testing and Materials, Philadelphia, PA, pp. 53-69.

Plesha, M.E., Ballarini, R., Parulekar, A., 1988, "A Constitutive Model and Finite Element Solution Procedure for Contact Friction Problems, "submitted to the ASCE Journal of Engineering Mechanics.

Marshal1, D.B., Cox, B.N., Evans, A.G., 1985, "The Mechanics of Matrix Cracking in Brittle-Matrix Fiber Composites," Acta Metallurgica, Vol. 33, No. 11, pp. 2013-2021.

Weeton, J.W., Peters, D.M., and Thomas, K.L., 1987 , Engineer's Guide to Composite Materials, American Society for Metals, Metals Park, Ohio.
APPENDIX A - DERIVATION OF LHR ELEMENT STIFFNESS

For a homogeneous isotropic material, the stress strain relationship is given by

$$
\begin{array}{r}
\left\{\begin{array}{c}
\sigma_{x x} \\
\sigma_{y y} \\
\tau_{x y}
\end{array}\right\}=\frac{E}{(1+v)(1-2 v)}\left[\begin{array}{cc}
(1-v) & v \\
v & (1-v) \\
0 & 0
\end{array}\right. \\
\quad\left\{\begin{array}{c}
\varepsilon_{x x} \\
\varepsilon_{y y} \\
\varepsilon_{x y}
\end{array}\right\}
\end{array}
$$

or,

$$
\left\{\begin{array}{c}
\sigma_{x x} \\
\sigma_{y y} \\
\tau_{x y}
\end{array}\right\}=\left[\begin{array}{lll}
E_{11} & E_{12} & E_{13} \\
E_{21} & E_{22} & E_{23} \\
E_{31} & E_{32} & E_{33}
\end{array}\right]\left\{\begin{array}{c}
\varepsilon_{x x} \\
\varepsilon_{y y} \\
\varepsilon_{x y}
\end{array}\right\}
$$

The continuum is modeled by a set of spring elements as described previously. The values of the spring constants are related to the material's elastic properties by the following relationships:

$$
\left.\begin{array}{rl}
K_{x y}^{i j} & =E_{12} \\
K_{x x}^{i j} & =\frac{b E_{11}}{a} \\
K_{y y}^{i j} & =\frac{a E_{22}}{b}
\end{array}\right\}
$$$$
c_{i}=\frac{a \cdot b \cdot E_{33}}{2} \text { for all } i, j=1, \ldots, 4
$$

where $a$ and $b$ are the length ( $x$-direction) and width (y-direction) of the LHR element respectively; $K_{x x}^{i j}$ is the extensional stiffness in the $x$-direction between the $i^{\text {th }}$ and $j^{\text {th }}$ nodes; $K_{y y}^{i j}$ is the extensional stiffness in the $y$-direction between the $i^{\text {th }}$ and $j^{\text {th }}$ nodes; $K_{x y}^{i j}$ is the cross extensional component (Poisson's contraction effect); and $C_{j}$ is the rotational stiffness at each node.

The above relationships are derived as follows. Consider a finite continuum element of dimensions $a \times b$, which is modeled by a LHR spring element of the same dimensions. By forcing the spring element to

\section{ORTITNAL PAGE IS \\ Ol: Dis iR QUALTTY}


behave like the continuum element, appropriate relationships may be obtained for the spring stiffnesses, $K_{x x}$, $K_{x y}, K_{y y}$, and $c_{j}$. Since the material is isotropic,

$$
\begin{gathered}
k_{x x}^{12}=k_{x x}^{34}=k_{x x} ; \quad x_{y y}^{14}=k_{y y}^{23}=k_{y y} ; \\
k_{x y}^{12}=k_{x y}^{23}=k_{x y}^{34}=k_{x y}^{14}=k_{x y}^{14}=k_{x y}
\end{gathered}
$$

and

$$
c_{1}=c_{2}=c_{3}=c_{4}=c \text {. }
$$

Consider the continuum element under a state of uniform strain $\varepsilon_{x x}(F i g$. Al). If $\Delta x$ represents the extension of the element in the $x$-direction, then, $\Delta x / a=\varepsilon_{x x}$; or, $\Delta x=\varepsilon_{x x}$. The stresses in the element are given by $\sigma_{x x}=E_{1} \varepsilon_{x x}$ and the force in the $x$-direction in the element is

$$
F_{x}=\sigma_{x x} b=E_{11^{\varepsilon_{x x}}}{ }^{b}
$$

Imposing an equivalent extension in the $x$-direction on the spring element, the force in the $x$-direction at the nodes 2 and 3 are given by $K_{x x} \Delta x$ $=k_{x x} \varepsilon_{x x^{a}}$. The total force in the $x$-direction in the element is

$$
F_{x}=\frac{F_{x 1}+F_{x 2}}{2}=K_{x x} \varepsilon_{x x}{ }^{a}
$$

Hence from Eqs. (A2) and $(A 3) K_{x x}=\left(E_{\eta} b\right) / a$.

Similarly, by considering a uniform strain $\varepsilon_{y y}$ in the $y$-direction, it may be shown that $K_{y y}$ $=\left(E_{22} a\right) / b$.

From Eq. (Al), the stress in the y-direction, $\sigma_{y y}$, in the continuum element due to strain $\varepsilon_{x x}$ is $o_{y y}=E_{2} \varepsilon_{x x}=E_{12 \varepsilon_{x x}}$ and the force in the $y$-direction is

$$
F_{y}=\sigma_{y y^{a}}=E_{12^{\varepsilon}} x x^{a}
$$

If $K_{x y}$ is the cross-extensional stiffness coefficient of the spring element, then, the force in the $y$-direction due to displacement $\Delta x$ is:

$$
F_{y}=K_{x y} \Delta x=K_{x y} \varepsilon_{x x^{2}}
$$

From Eqs. (A4) and (A5) we have $K_{x y}=E_{12}$.

Finally, consider the continuum element in a state of pure shear (shear strain, $\varepsilon_{x y}$ ), as shown in Fig. A2. The shear stress in the element is $\tau_{x y}=\tau_{y x}=E_{33} \varepsilon_{x y}$. The force in the $x$-direction on face $1-2$ of the element is:

$$
F_{x}=\tau_{x y} a=E_{33^{\varepsilon}} x_{y}{ }^{a}
$$

Imposing the corresponding nodal rotations in the spring element ( $F i g$. A3), the force in the $x$-direction of the side $1-2$ of the element is:

$$
F_{x}=\frac{2 C \theta}{b}=\frac{2 C \varepsilon_{x y}}{b}
$$

Hence $C=E_{33} a b / 2$.

Having obtained the spring stiffnesses in terms of the elastic constants, the stiffness matrix of a LHR element may now be formulated. The stiffness coefficients can be evaluated through energy considerations as follows. The total strain energy $U$ stored in an element for any set of arbitrarily varied nodal displacements $u_{i}$ and $v_{i}$ may be written as (refer to Fig. 5 in the text)

$$
\begin{aligned}
u & =\frac{1}{2} k_{x x}\left(u_{2}-u_{1}\right)^{2}+\frac{1}{2} k_{x x}\left(u_{3}-u_{4}\right)^{2} \\
& +\frac{1}{2} k_{y y}\left(v_{4}-v_{1}\right)^{2}+\frac{1}{2} k_{y y}\left(v_{3}-v_{2}\right)^{2} \\
& +\frac{k_{x y}\left(v_{4}-v_{1}+v_{3}-v_{2}\right)\left(u_{2}-u_{1}+u_{3}-u_{4}\right)}{2} \\
& +\frac{1}{2} c\left(\frac{v_{2}-v_{1}}{a}+\frac{u_{4}-u_{1}}{b}\right)^{2}+\frac{1}{2} c\left(\frac{u_{3}-u_{2}}{b}+\frac{v_{2}-v_{1}}{a}\right)^{2} \\
& +\frac{1}{2} c\left(\frac{u_{3}-u_{2}}{b}+\frac{v_{3}-v_{4}}{a}\right)^{2}+\frac{1}{2} c\left(\frac{u_{1}-u_{4}}{b}+\frac{v_{4}-v_{3}}{a}\right)^{2}
\end{aligned}
$$

Using Castigliano's theorem, the nodal forces can be obtained as follows:

$$
\left.\begin{array}{l}
F_{x i}=\frac{\partial U}{\partial u_{i}} \\
F_{y i}=\frac{\partial U}{\partial v_{i}}
\end{array}\right\}
$$

Such derivatives for each joint give the element stiffness matrix in the form

$$
\{F\}=[K]\{d\}
$$

where [K] represents the element stiffness matrix, (d) the displacement vector, and $\{F\}$ the element force vector.

Assembly of the LHR stiffness matrix is done by standard direct stiffness methods employed in finite element practice.

APPENDIX B - DERIVATION OF THE STRAIN ENERGY RELEASE RATE FOR INCIPIENT RUPTURE

Consider a small virtual increase $\Delta c$ in crack length in an element under a given external load. The total potential energy, $\pi$, is given by

$$
\pi=\frac{1}{2}\{u\}^{\top}[K]\{u\}-\{u\}^{\top}(b\}
$$

where $\{u\}$ is the nodal displacement vector, [K] is the element stiffness matrix, and $\{b\}$ is the nodal force vector.

The energy release rate $G$ is obtained from the variation of $\pi$ with respect the load, i.e.,

$$
\begin{aligned}
\delta \pi=\frac{1}{2}\{u\}^{\top}[\delta k]\{u\}+\{\delta u\}^{\top}[K]\{u\} & \\
& -\{\delta u\}^{\top}\{b\}-\{u\}^{\top}\{\delta b\}
\end{aligned}
$$

Using equilibrium and the fact that the vector $\{\delta b\}$ is null for a given load, the above simplifies to 


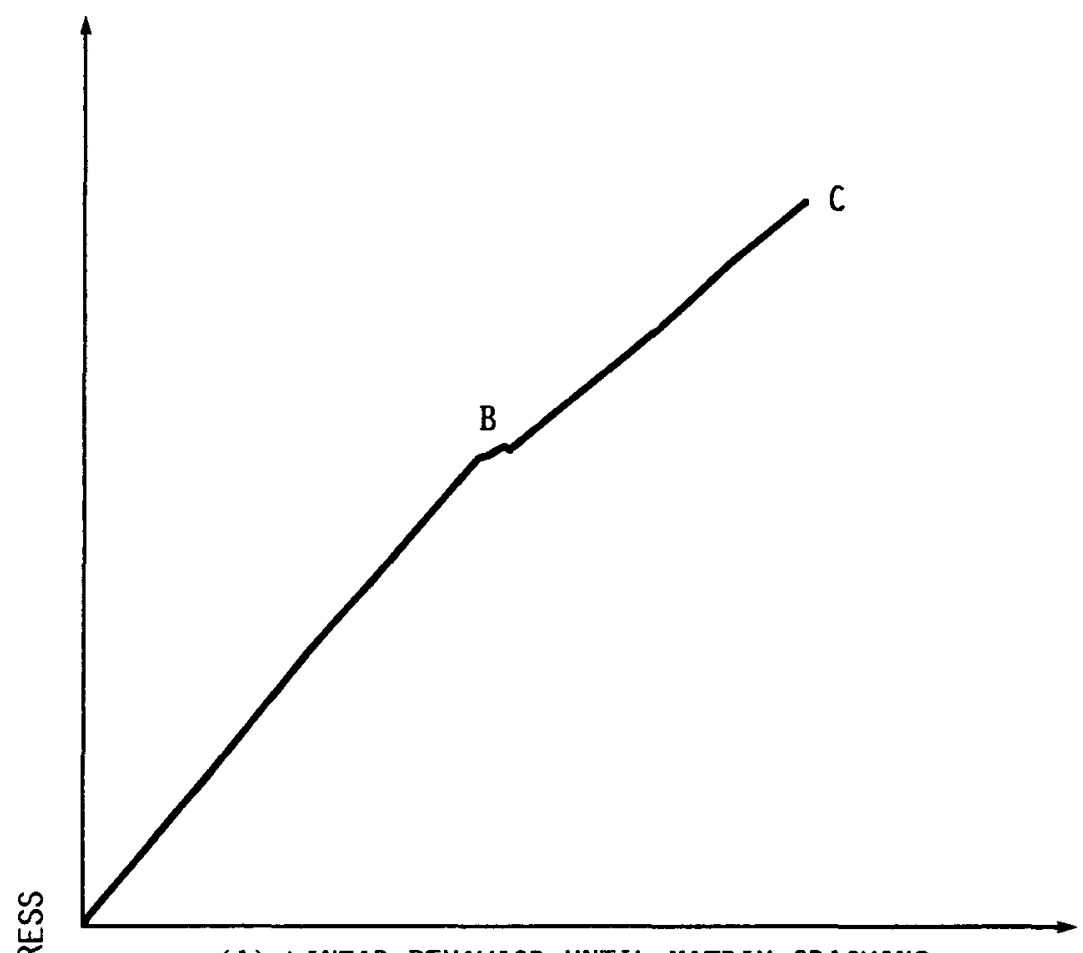

(A) LINEAR BEHAVIOR UNTIL MATRIX CRACKING.

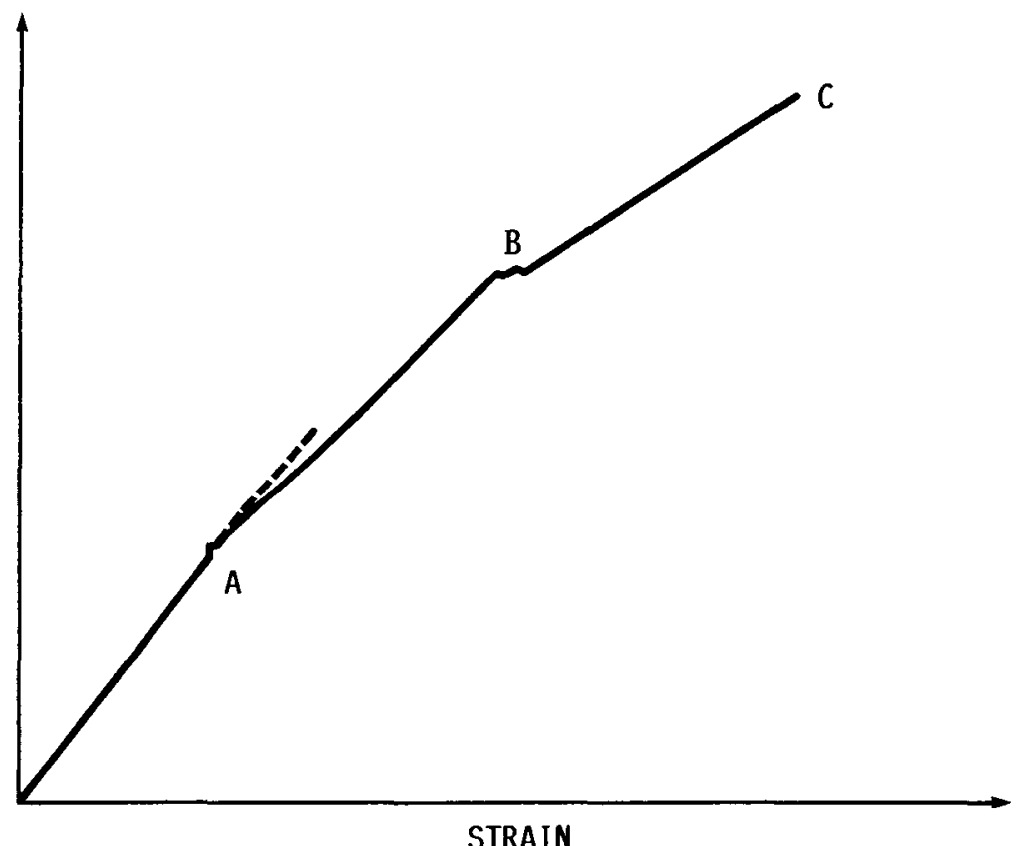

(B) OBTAINED BY USING LUR MODEL.

FIGURE 1. - TYPICAL STRESS-STRAIN CURVE FOR BMC.

8 


$$
\delta \pi=\frac{1}{2}\{u\}^{\top}[\delta k]\{u\}
$$

Hence,

$$
G=-\frac{d \pi}{d c}=-\frac{1}{2}\{u\}^{\top} \frac{d}{d c}[K]\{u\}
$$

if $[\delta K]$ be the change in the stiffness matrix of the element due to the incipient fracture, i.e., [\$K] $=[K]_{\text {before }}-[K]_{\text {after, }}$, then $G$ may written in the form

$$
\Delta E_{S}=\frac{\{u\}^{\top}[\delta K]\{u\}}{2 \Delta c}
$$

TABLE I. - CONSTITUTIVE MATERIAL PROPERTIES

\begin{tabular}{|l|c|c|c|}
\hline Constituent & $\begin{array}{c}\text { Young's } \\
\text { modulus, } \\
\text { GPa }\end{array}$ & $\begin{array}{c}\text { Poisson's } \\
\text { ratio }\end{array}$ & $\begin{array}{c}\text { KIC, } \\
\text { MPa }\end{array}$ \\
\hline SiC fibers & 390 & 0.3 & 5.0 \\
$\mathrm{Si}_{3} \mathrm{~N}_{4}$ matrix & 206 & .3 & 4.6 \\
Interface & 206 & .3 & -- \\
\hline
\end{tabular}




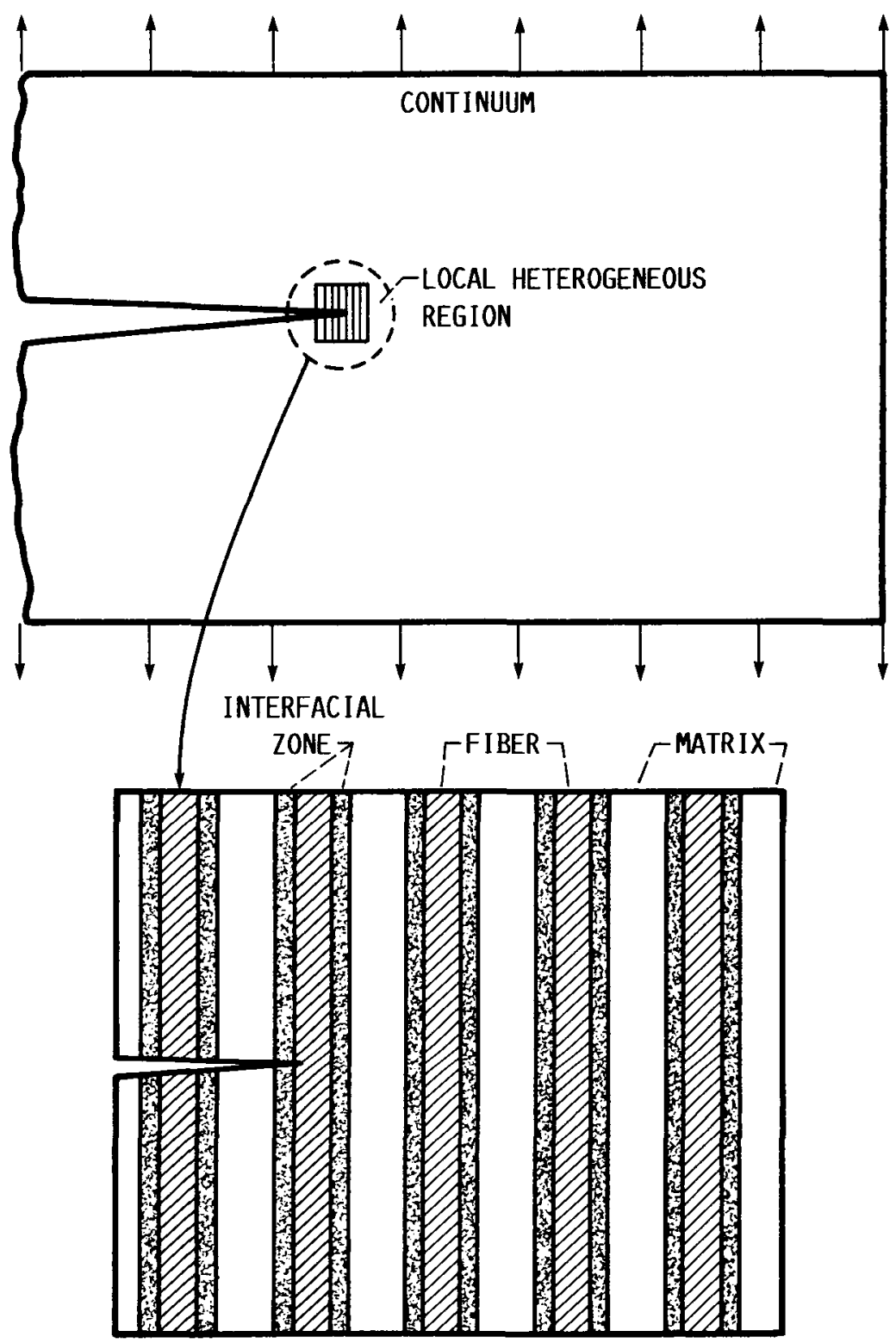

FIGURE 3. - LOCAL HETEROGENEOUS REGION (LHR) AND ITS COMPONENTS. 


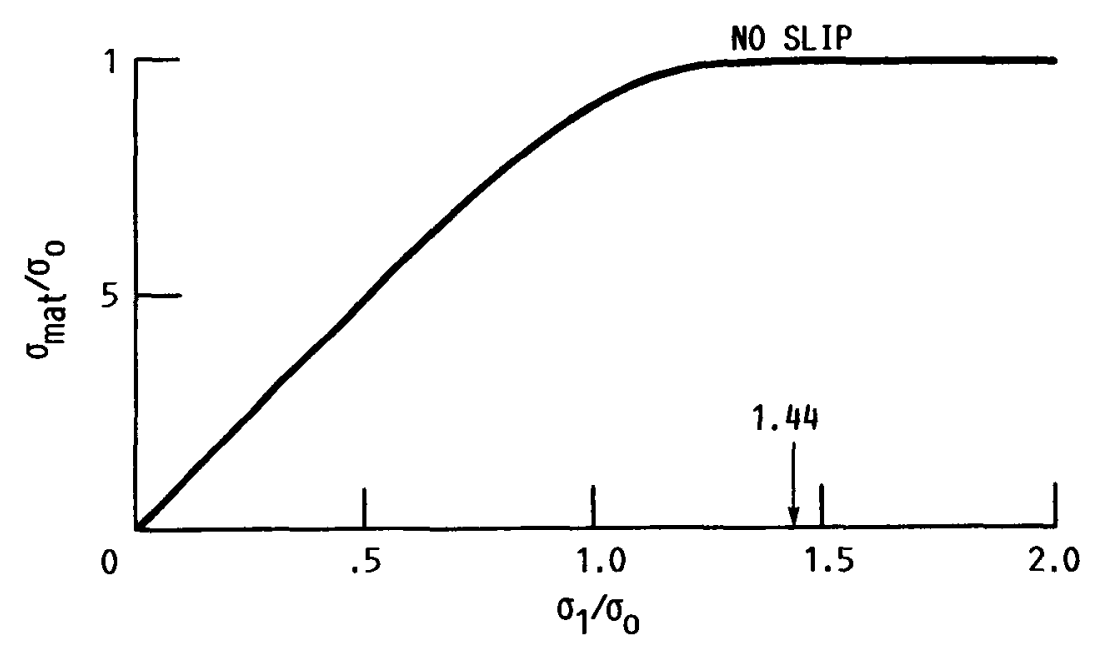

FIGURE 2. - GRAPH DUE TO BUDIANSKY ET AL., FOR CALCULATING MATRIX CRACKING STRESS. 
ORIGINAL PAGE IS

OF POOR QOALITY
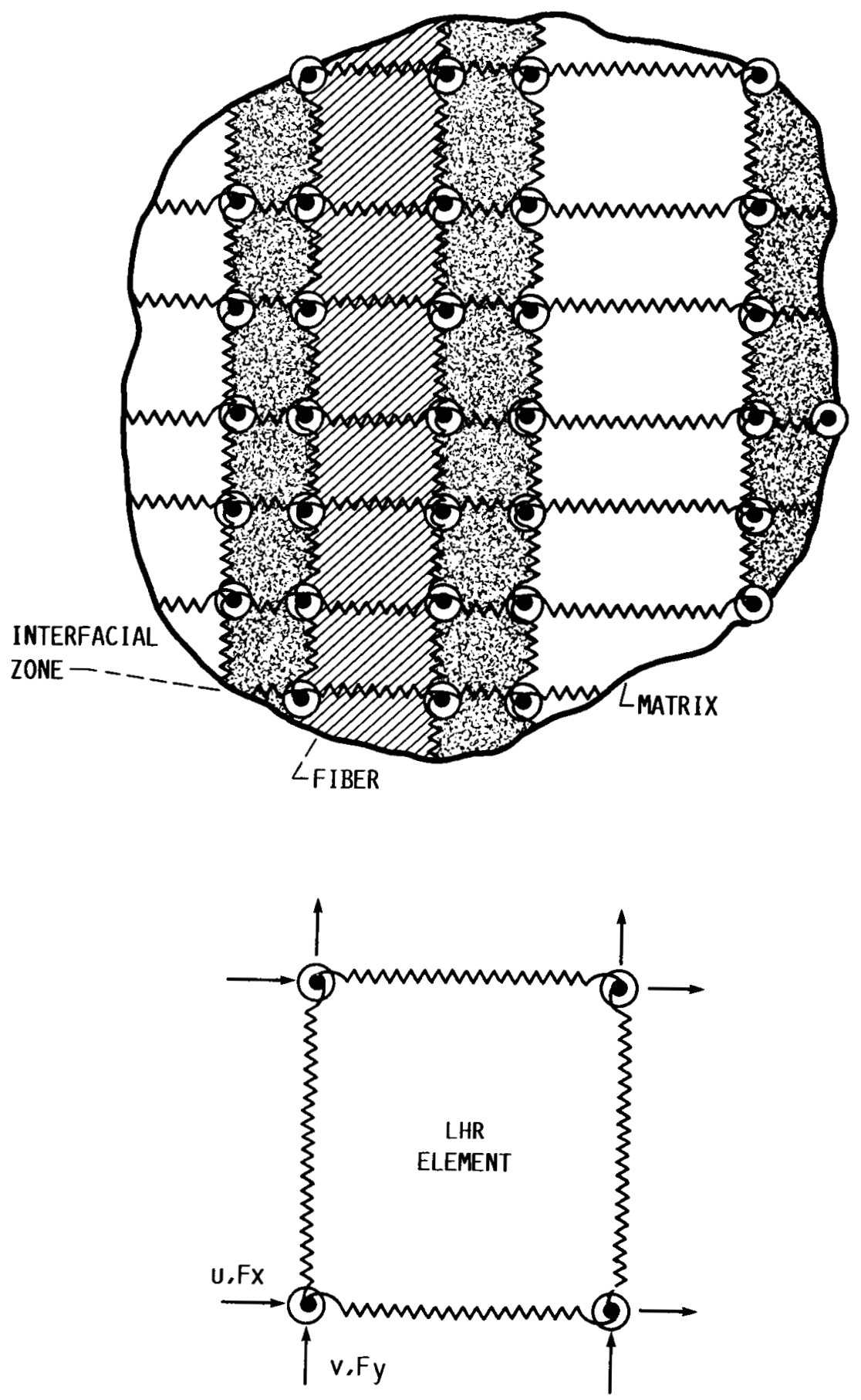

FIGURE 4. - SPRING MODEL OF THE LHR ZONE. 


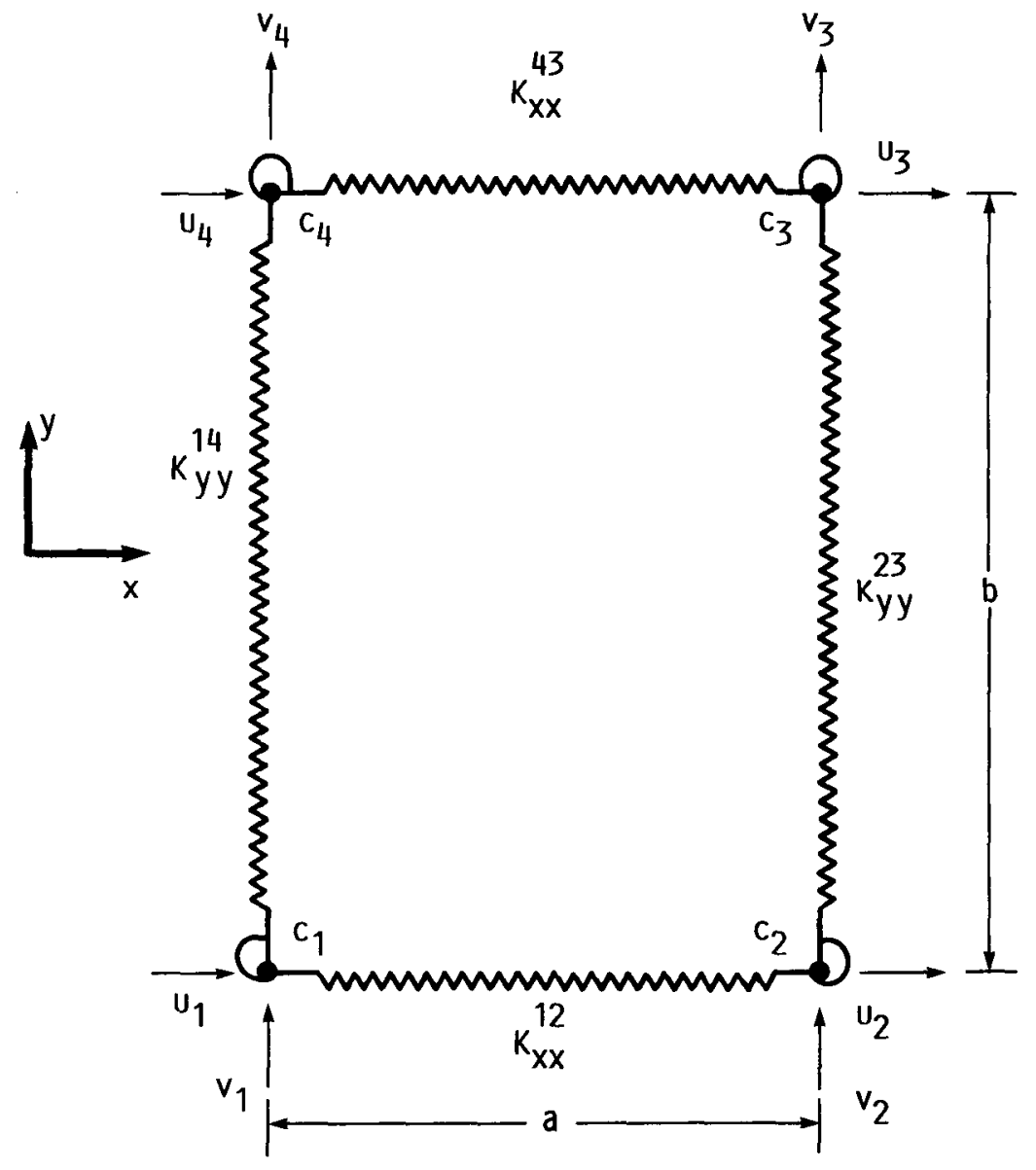

FIGURE 5. - LHR ELEMENT STIFFNESS COMPONENTS. 


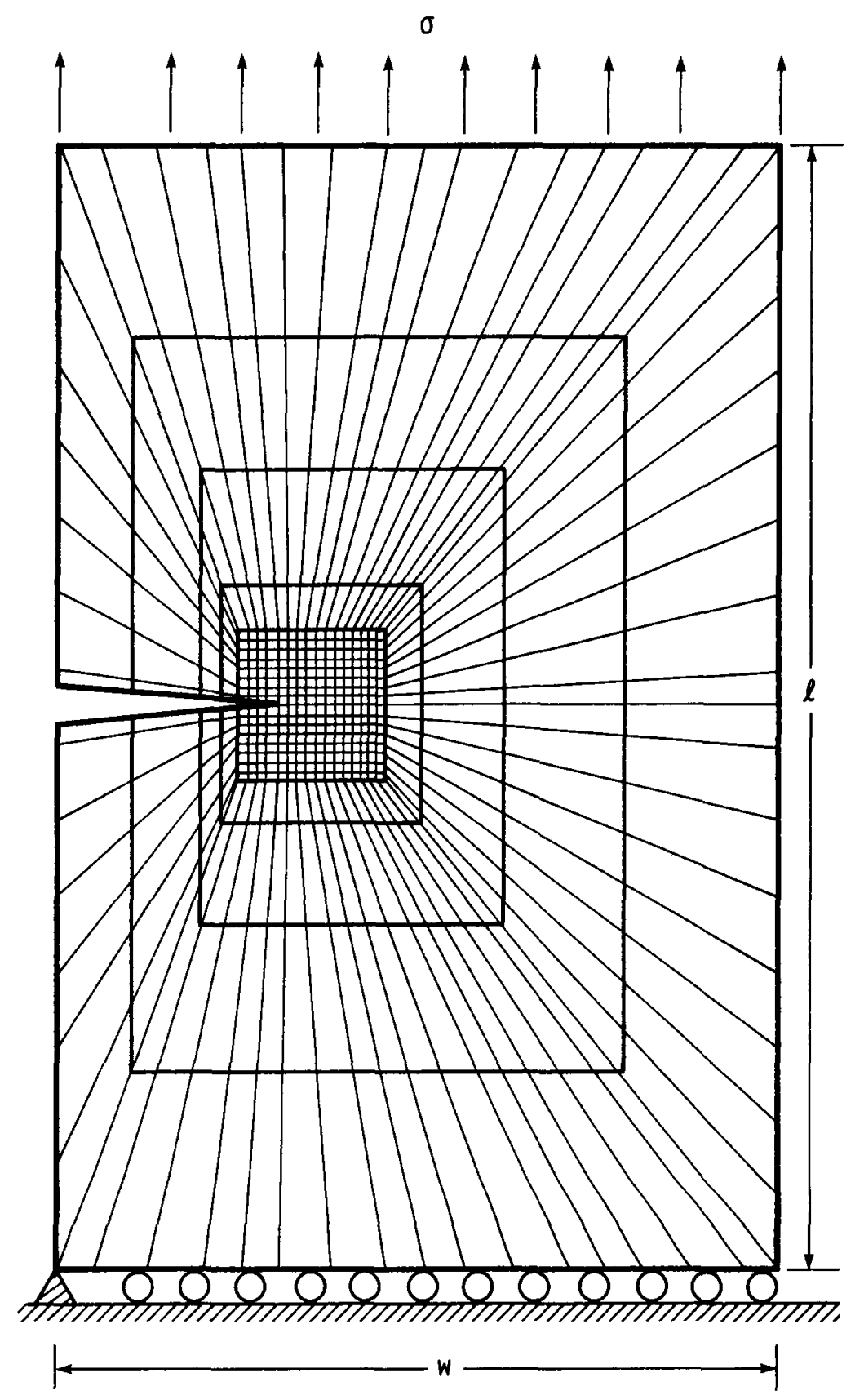

FIGURE 7. - SCHEMATIC OF THE LHR ZONE EMBEDDED IN THE FINITE ELEMENT MESH. (NOT TO SCALE). 


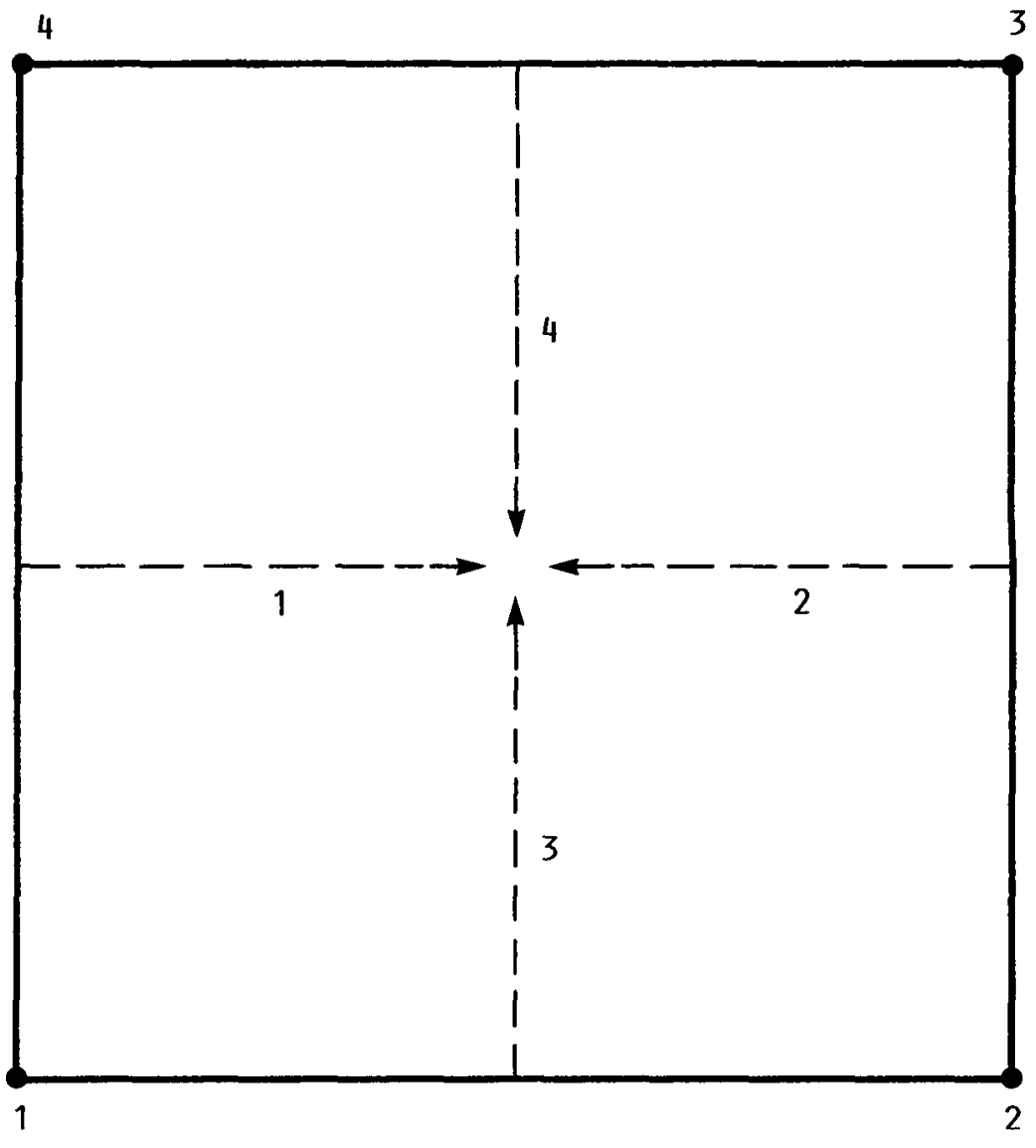

FIGURE 6. - LOCAL FRACTURE MODES IN A LHR ELEMENT. 


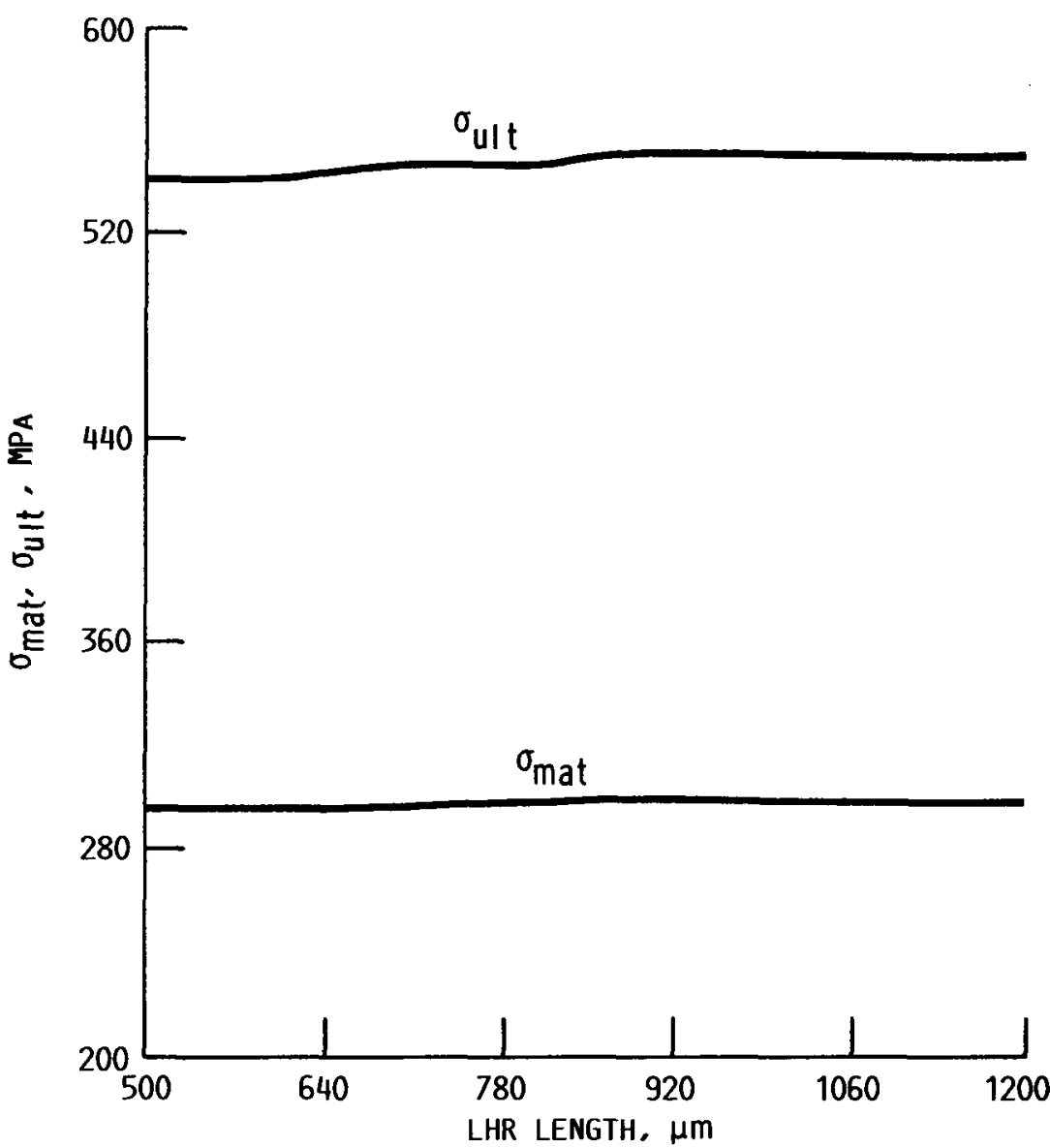

FIGURE 8. - EFFECT OF LHR LENGTH ON $\sigma_{\text {mat }}$ AND $\sigma_{u l t}$ $\left(v_{f}=0.4, \tau_{0}=10 \mathrm{MPA}, K_{I C}^{M}=4.6 \mathrm{MPA} \sqrt{\mathrm{M}}\right)$. 


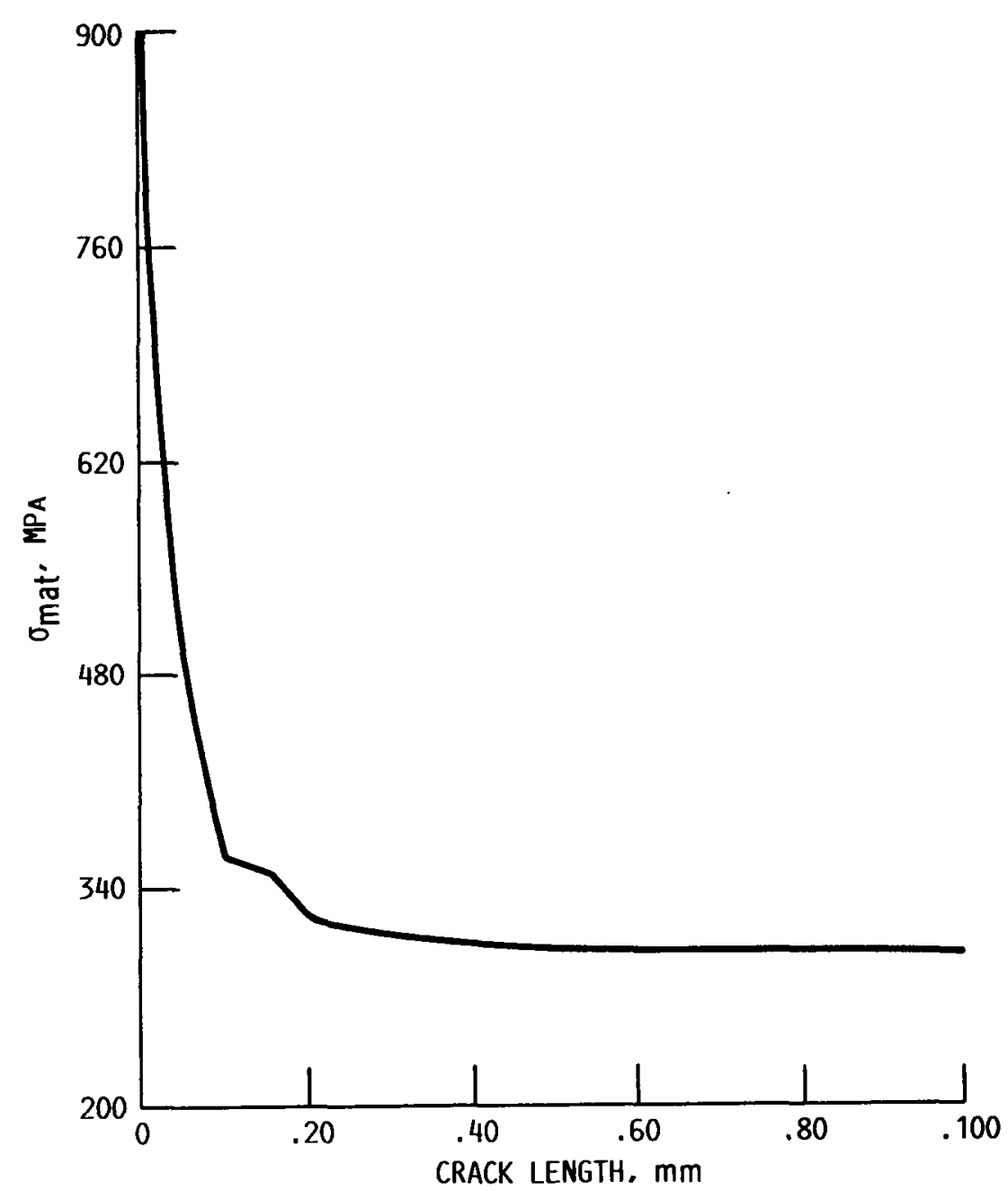

FIGURE 9. - VARIATION OF $\sigma_{\text {mat }}$ WITH CRACK LENGTH $C$ $\left(\tau_{0}=10 \mathrm{MPA}, K_{I C}^{M}=4.6 \mathrm{MPA} \sqrt{\mathrm{M}}, v_{f}=0.4\right)$. 


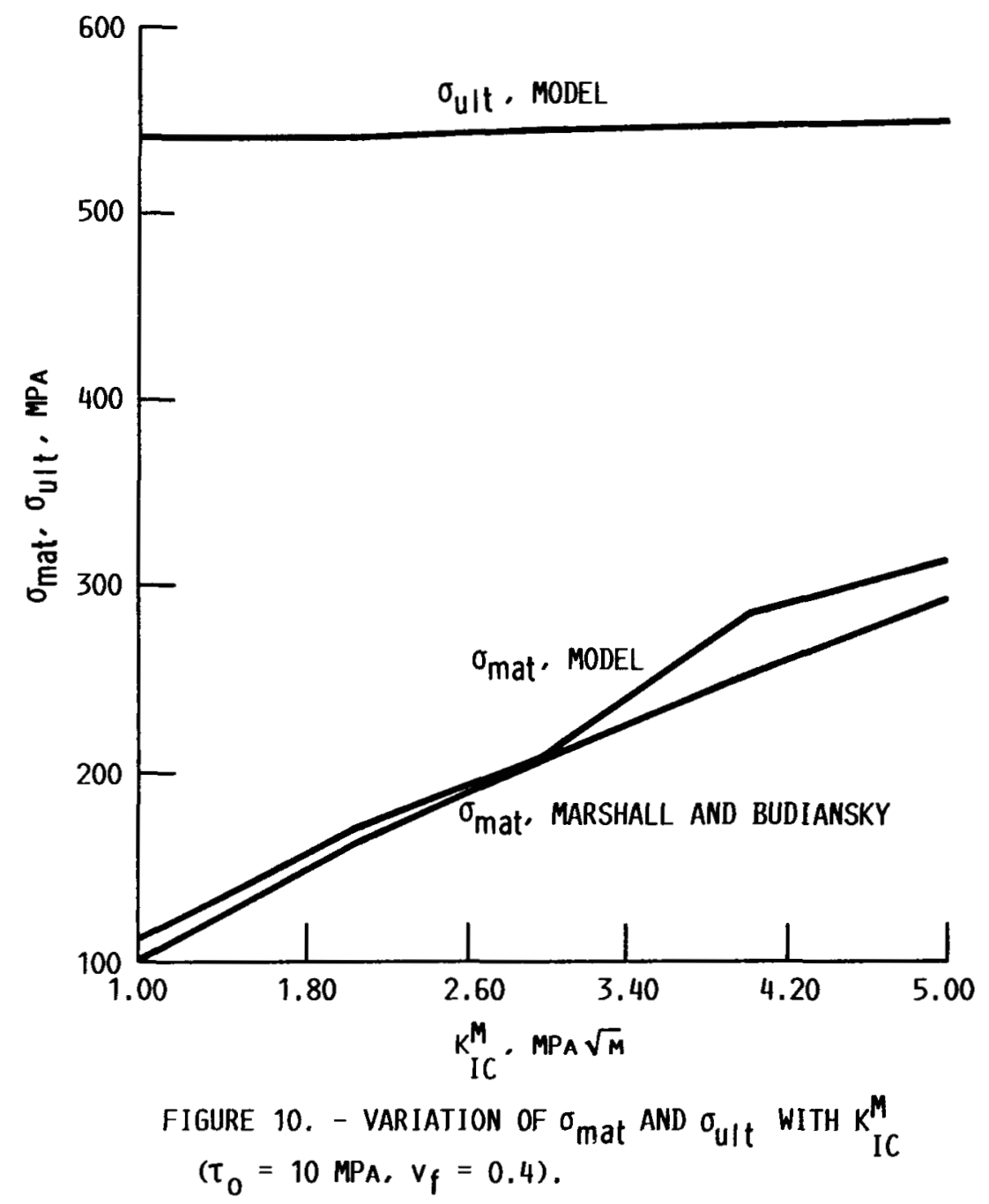




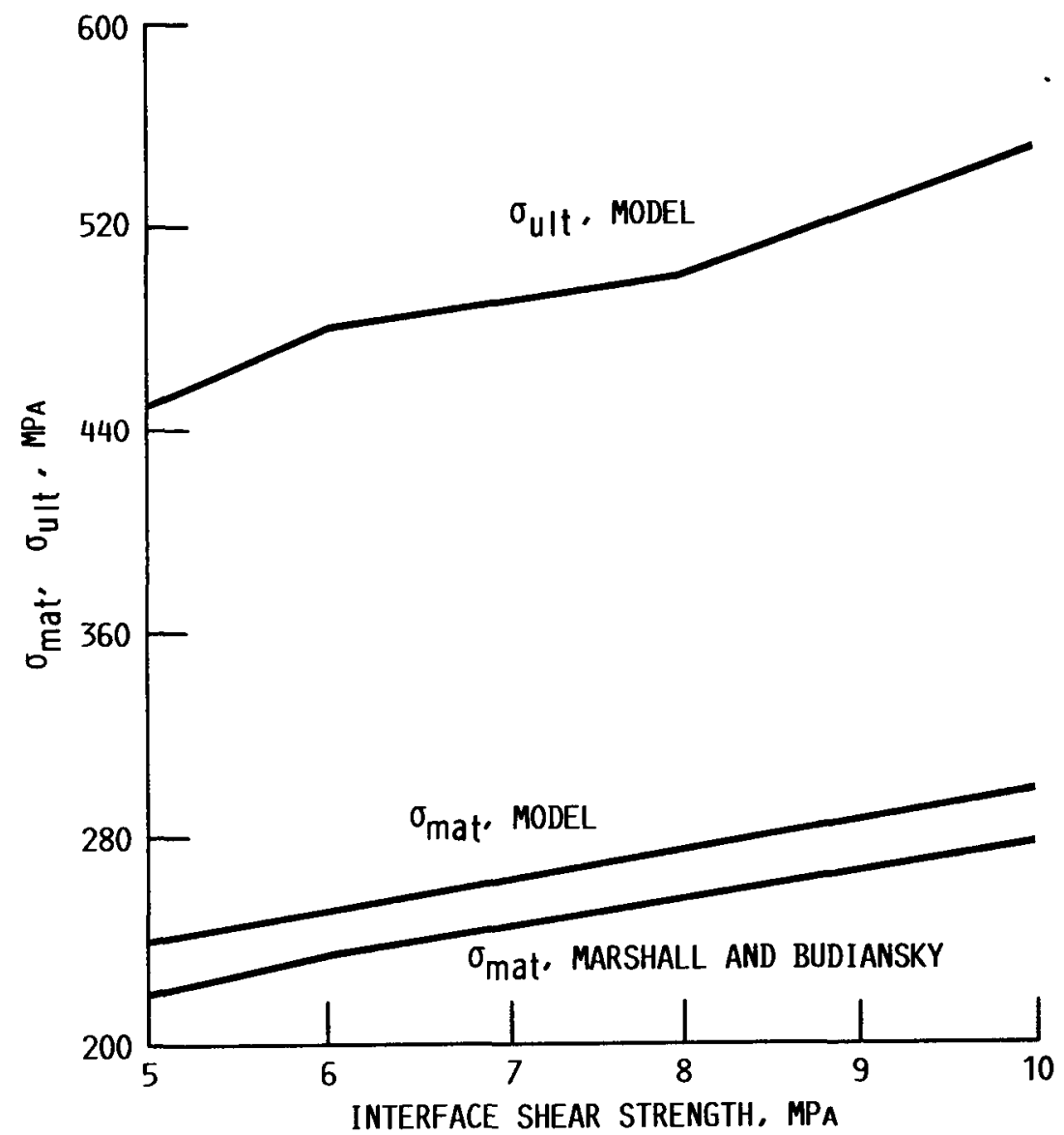

FIGURE 11. - VARIATION OF $\sigma_{\text {mat }}$ AND $\sigma_{u I t}$ WITH $\tau_{0}$ $\left(K_{I C}^{M}=4.6\right.$ MPA $\left.\sqrt{M}, v_{f}=0.4\right)$. 


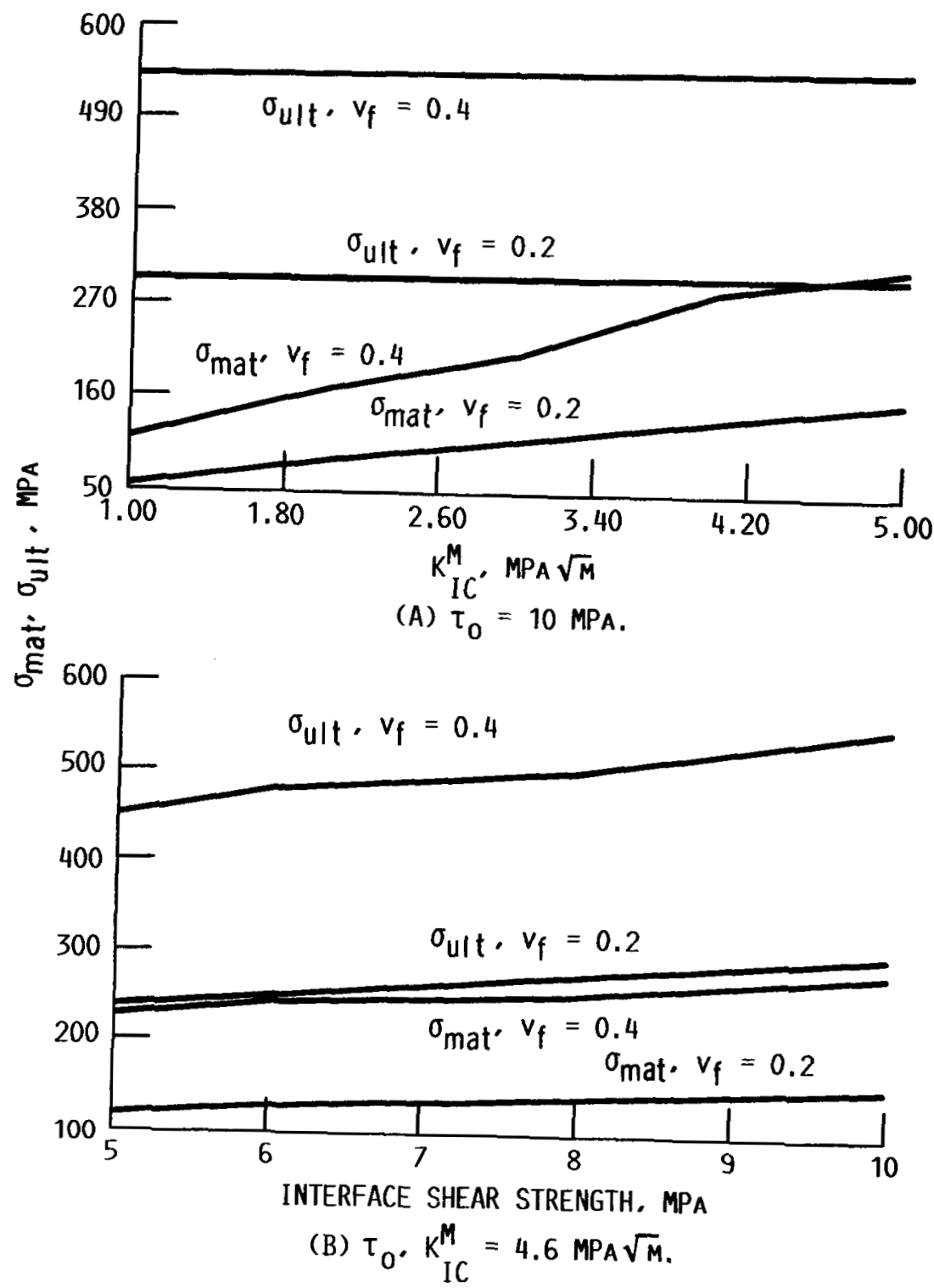

FIGURE 12. - EFFECT OF FIBER VOLUME FRACTION, $v_{f}$. ON $\sigma_{\text {mat }}$ AND $\sigma_{u l t}$ VARIATION WRT. 


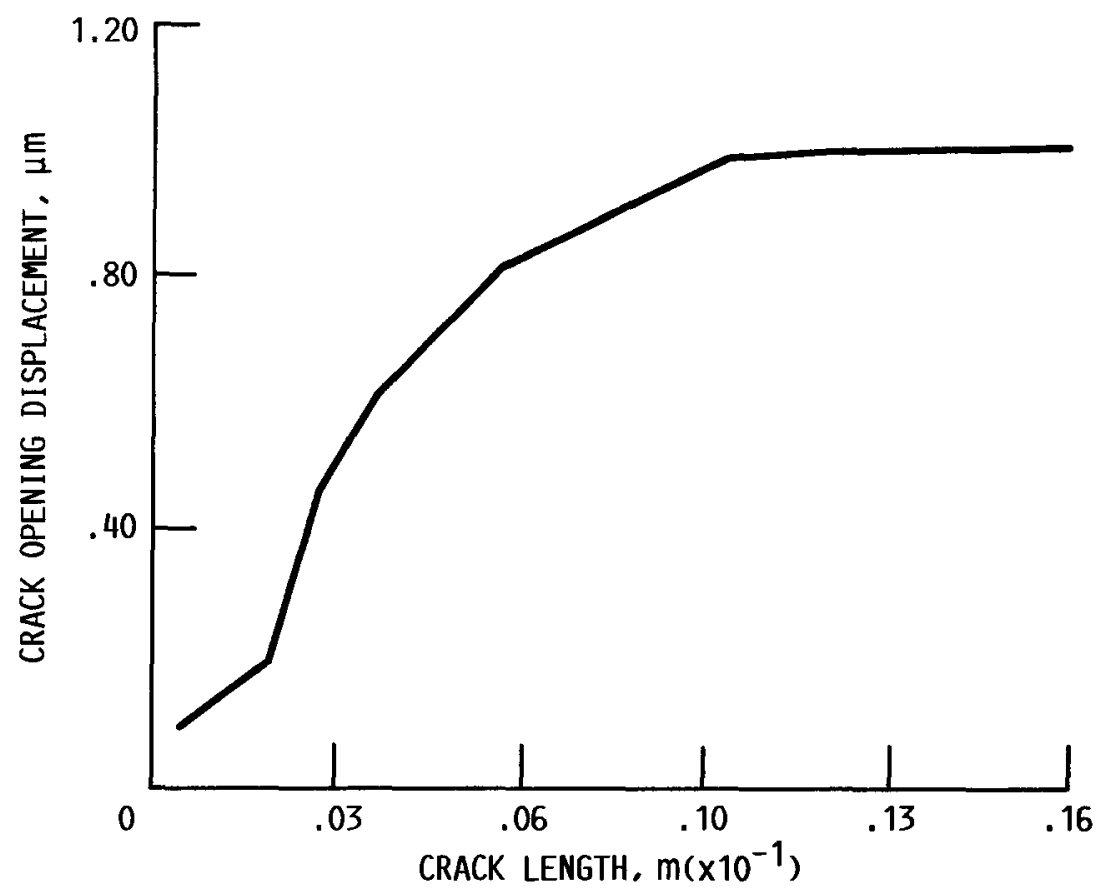

FIGURE 13. - VARIATION OF CRACK OPENING DISPLACEMENT

$u_{0}$ WITH CRACK LENGTH $c\left(\tau_{0}=10\right.$ MPA, $K_{I C}^{M}=$

4.6 MPA $\left.\sqrt{M}, v_{f}=0.4\right)$. 
$\begin{array}{llllllllllllllllllllllll}M & I & F & I & M & I & F & I & M & I & F & I & M & I & F & I & M & I & F & I & M & I & F & I\end{array}$

\begin{tabular}{|l|l|l|l|l|l|l|l|l|l|l|l|l|l|l|l|l|}
\hline & 17 & & & & & 17 & & & & & & & \\
\hline & 5 & & & & & & & & & 17 & & & & \\
\hline 9 & 4 & & 4 & & 5 & 17 & & & 16 & & & 17 & 10 & 17 & & \\
\hline & 3 & 16 & 3 & $9 *$ & 5 & & & & 16 & & 17 & & & & \\
\hline 9 & 3 & 16 & 2 & 8 & 5 & 15 & 5 & 9 & 5 & & & 16 & & 17 & & \\
\hline 3 & & 2 & & 5 & 15 & 5 & 9 & 5 & 15 & 9 & 16 & $10^{*}$ & & 13 & \\
\hline 6 & 2 & & 1 & 7 & 4 & & 4 & 8 & 4 & & 9 & 16 & 10 & 17 & 13 & \\
\hline 6 & 2 & 14 & 1 & 6 & 3 & & 4 & & 4 & 15 & & 16 & & 17 & 13 & \\
\hline
\end{tabular}

\begin{tabular}{|c|c|c|c|c|c|c|c|c|}
\hline$6 \longdiv { 2 }$ & 14 & \begin{tabular}{|l|l}
1 & 6
\end{tabular} & & & 4 & $|4|$ & 15 & \\
\hline \begin{tabular}{l|l}
6 & 2 \\
\end{tabular} & & 17 & 4 & & \begin{tabular}{|l|l}
48 \\
\end{tabular} & 4 & & 9 \\
\hline & 16 & 2 & 5 & 15 & 59 & 5 & 15 & 9 \\
\hline \begin{tabular}{l|l}
93 \\
\end{tabular} & 16 & 28 & 5 & 15 & 59 & 5 & & \\
\hline 3 & & $39^{\prime}$ & 5 & & & & 16 & \\
\hline 94 & & 4 & 5 & 17 & & & 16 & \\
\hline 15 & & & & & & & & \\
\hline & 17 & & & & & & 17 & \\
\hline
\end{tabular}

EVENT \# LOAD, MPA

FAILURE EVENT

$\begin{array}{lll}1 & 140 & \text { FIRST INTERFACE FAILURE } \\ 2 & 150 & \text { INTERFACE FAILURE } \\ 3 & 200 & \text { INTERFACE FAILURE } \\ 4 & 250 & \text { INTERFACE FAILURE } \\ 4^{*} & 250-295 & \text { VARIOUS INTERFACE FAILURES } \\ 5 & 295 & \text { FIRST MATR IX CRACK } \\ 6 & 295.5 & \text { MATRIX AND INTERFACE FAILURE } \\ 7 & 296 & \text { MATRIX AND INTERFACE } \\ 8 & 297 & \text { MATRIX AND INTERFACE } \\ 9 & 298 & \text { MATRIX AND INTERFACE } \\ 10 & 299 & \text { MATRIX AND INTERFACE } \\ 11 & 300-305 & \text { THROUGH MATRIX CRACK } \\ & & \text { (BEYOND REGION SHOWN) } \\ 12 & 305-500 & \text { EXTENSIVE SECONDARY MATRIX } \\ & & \text { CRACKING (NOT SHOWN) } \\ 13 & 505 & \text { FIRST FIBER FAILURE } \\ 14 & 510 & \text { FIBER } \\ 15 & 515 & \text { FIBER } \\ 16 & 540 & \text { EXTENSIVE FIBER CRACKING } \\ 17 & 550 & \text { ULTIMATE (CATASTROPHIC) }\end{array}$

FAILURE

(EVENTS MARKED WITH AN ASTERICK (*) DENOTE VERTICAL CRACKING WITHIN AN LHR ELEMENT)

FIGURE 14. - SCHEMATIC REPRESENTATION OF THE PRINCIPAL FAILURE EVENTS IN THE LHR ZONE. $\left(\tau_{0}=10 \mathrm{MPA}, \mathrm{K}_{\mathrm{IC}}^{\mathrm{M}}=4.6 \mathrm{MPA} \sqrt{\mathrm{M}}, v_{f}=0.4\right)$. 


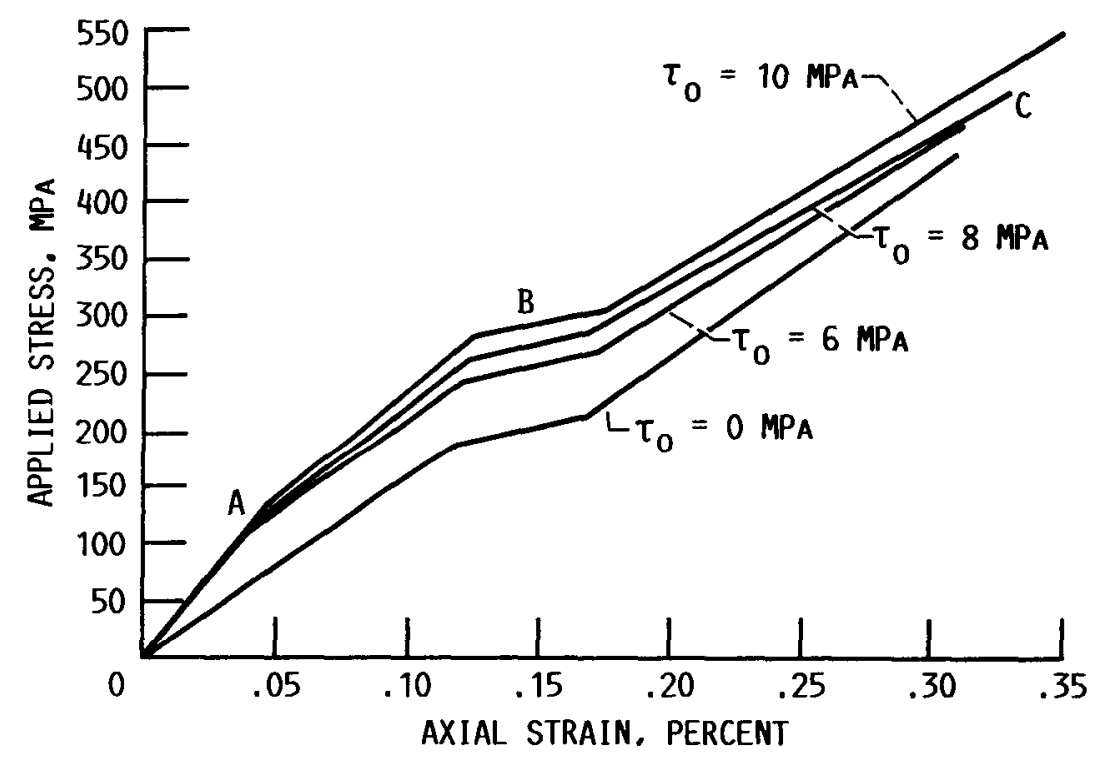

FIGURE 15. - AXIAL LOAD DEFLECTION CURVE FOR VARIOUS $\tau_{0}$ VALUES. $\quad\left(K_{I C}^{M}=4.6 \mathrm{MPA} \sqrt{M}, v_{f}=0.4\right)$. 

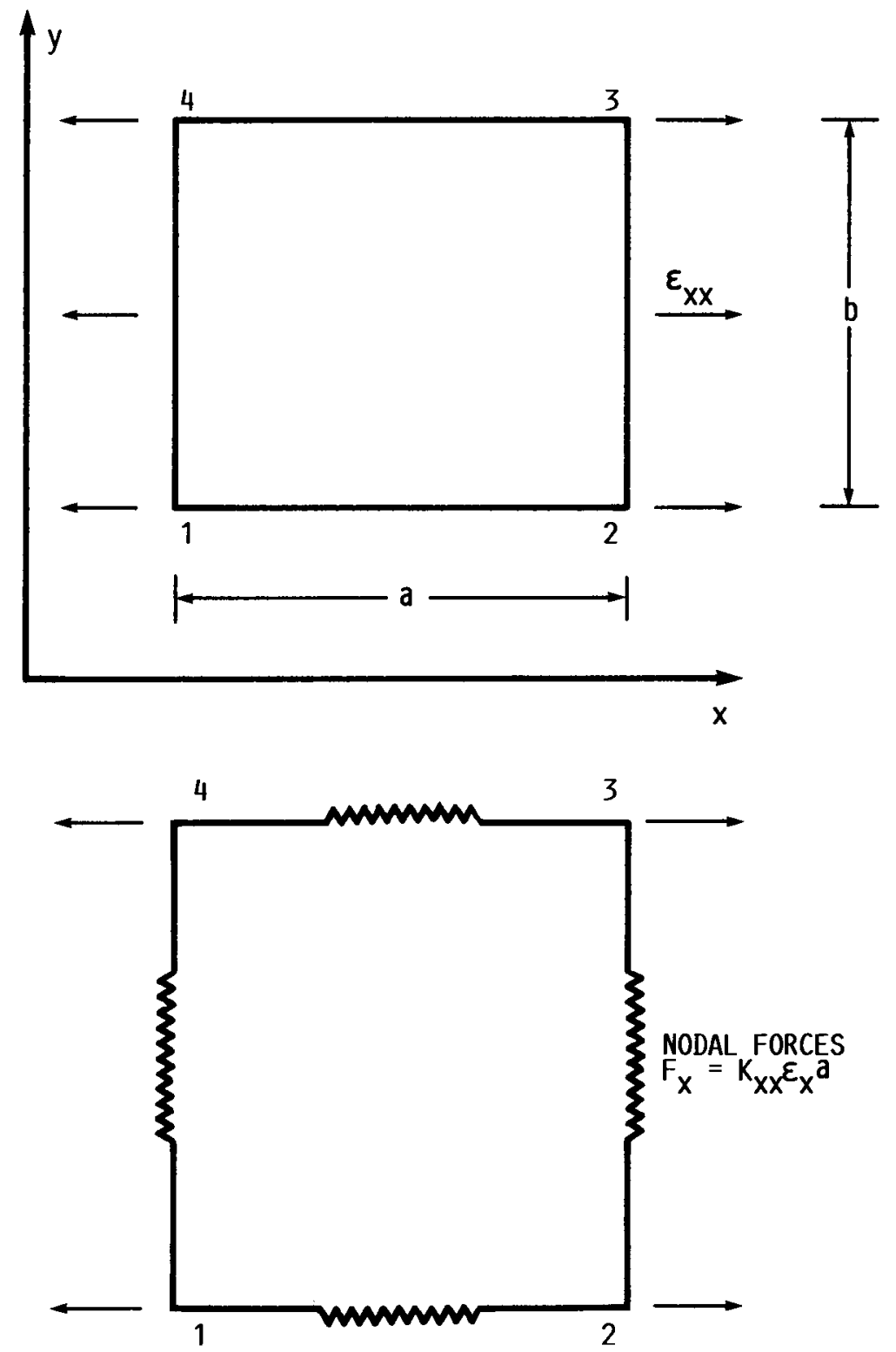

FIGURE A1. - FINITE CONTINUUM ELEMENT UNDER UNIFORM STRAIN AND EQUIVALENT LHR ELEMENT. 


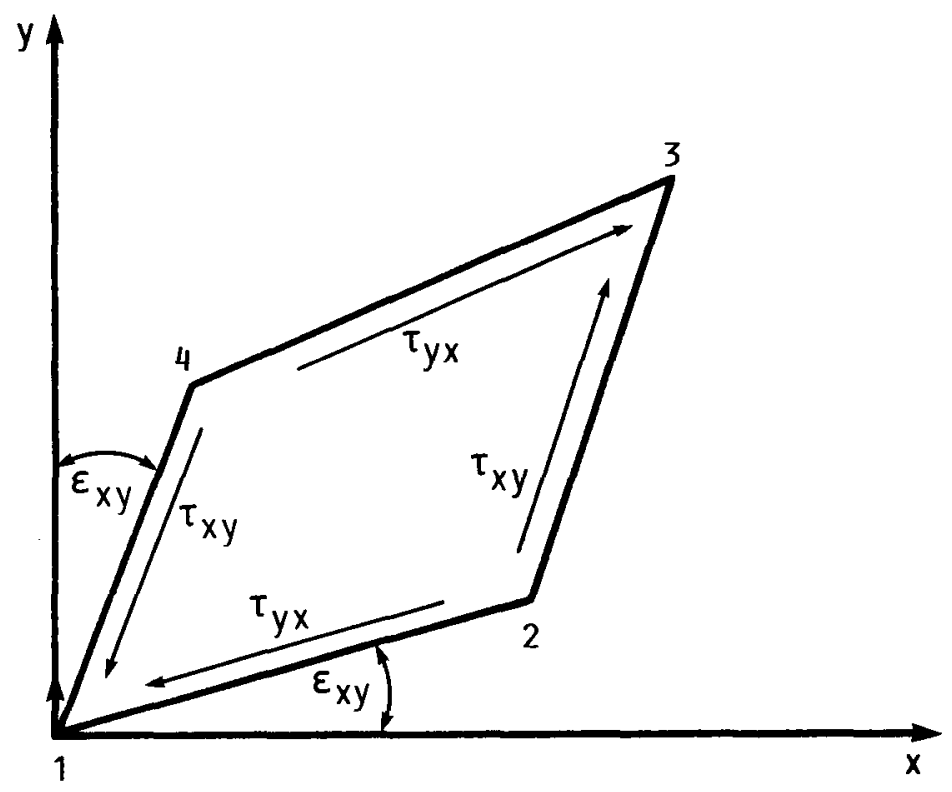

FIGURE A2. - CONTINUUM ELEMENT IN PURE SHEAR.

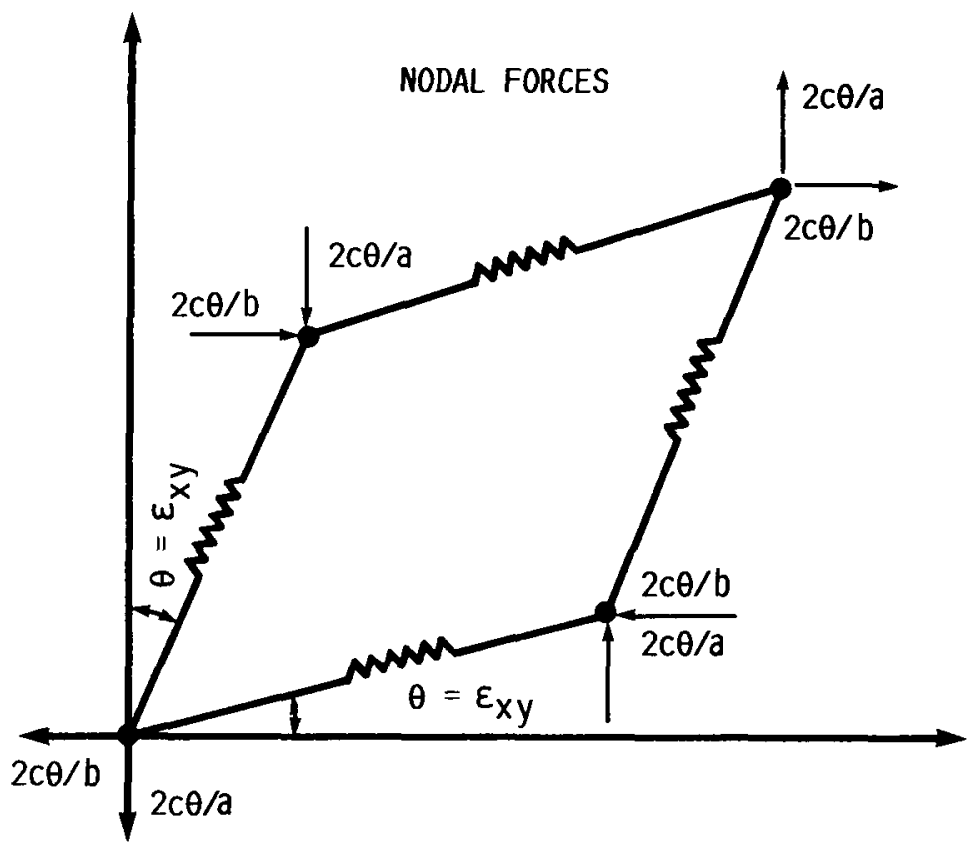

FIGURE A3. - LHR ELEMENT IN PURE SHEAR. 


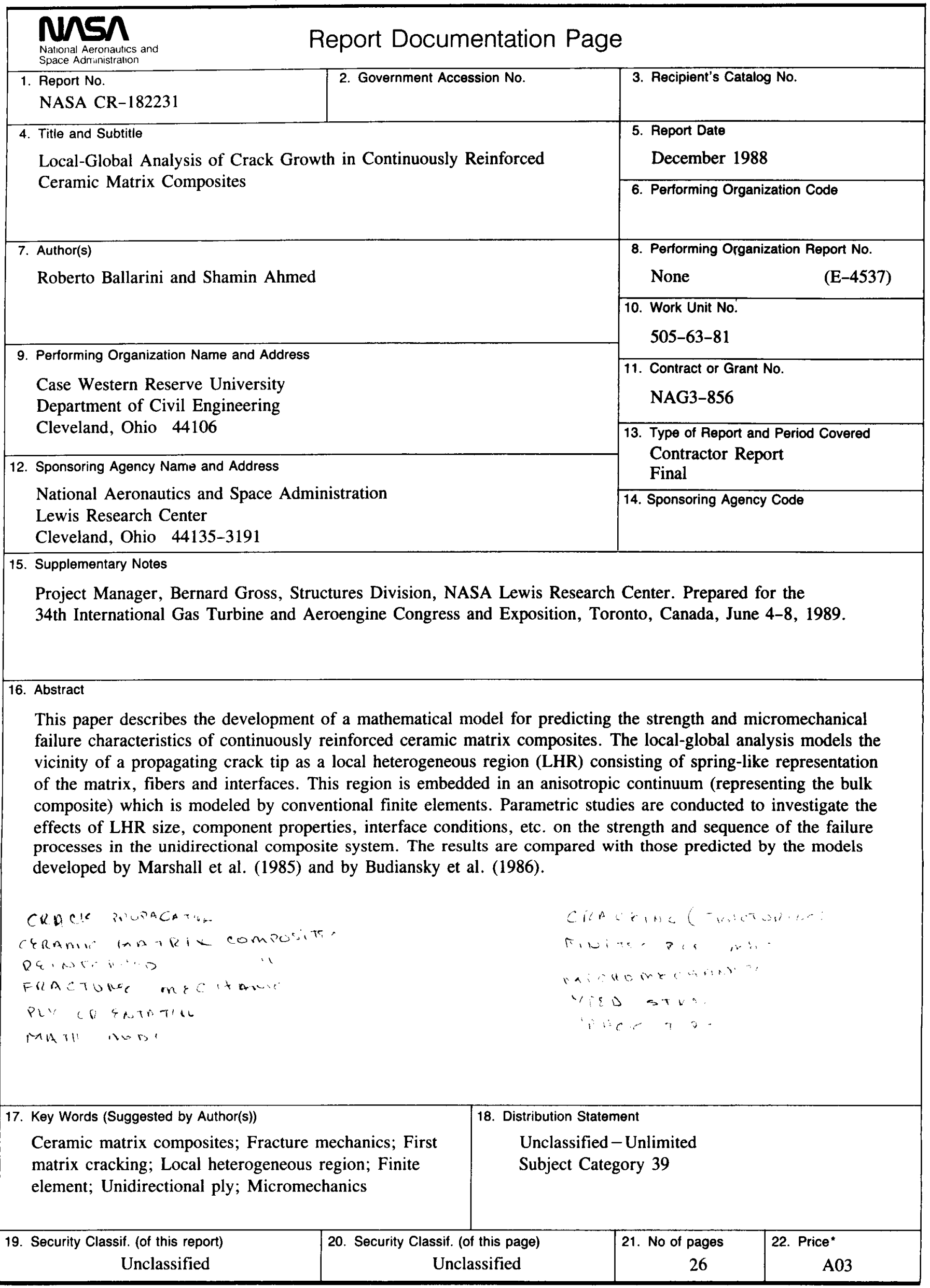


National Aeronautics and

Space Administration

Lewis Research Center

Cleveland, Ohio 44135

Ofticial Business

Penalty for Private Use $\mathbf{3 3 0 0}$
FOURTH CLASS MAll.

ADDRESS CORAECTION REQUESTED
$|1| \mid$

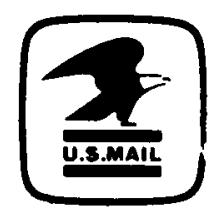

Postage and Fees Pials National Aerondutir siand Space Administratur in NASA 451 